\title{
Evaluation of Transportation Infrastructure and Urban Space of Tehran based on The Indicators of Age Friendly City
}

Fatemeh Estebsari

Assistant Professor, Ph.D. in Health Education \& Promotion. Dept. of Community Health Nursing, School of Nursing and Midwifery, Shahid Beheshti University of Medical Sciences (SBUMS), Tehran, Iran.

Zahra Rahimi Khalifeh Kandi

* PhD Candidate of Health Education\& Promotion Department of Health Education, School of Public Health, Iran University of Medical Sciences, Tehran, Iran. (Corresponding Author) tarla1367@yahoo.com

Maliheh Nasiri

Assistant Professor .Department of Biostatistics, School of Nursing and Midwifery, Shahid Beheshti University of Medical Sciences, Tehran, Iran.

Marjan Moradi Fath

Nursing Student. Student Research Committee, Shahid Beheshti University of Medical Sciences, Tehran, Iran.

Farank Karimi Yeganeh

Master of Science in Demography, Azna Health Network, Lorestan University of Medical Sciences, Lorestan, Iran

Davoud Mostafaei

PhD of Health Services Management, Shahid Beheshti University of Medical Sciences, Tehran, Iran

Received: 2021/01/01

Accepted: 2021/05/09

Doi: 10.52547/ijhehp.9.2.187

\section{ABSTRACT}

Background and Objective: The Age Friendly City has been proposed by the World Health Organization to achieve Active Aging. The aim of this study was to evaluation of transportation infrastructure and urban space of Tehran city based on the indicators of Age Friendly City.

Materials and Methods: The present cross-sectional study examined the views of 418 elderly residents of Tehran on the indicators of the World Health Organization's Age-Friendly City in terms of Outdoor Spaces and Buildings, Housing, Transportation and Community Support and Health Services in 1398. Data were collected using Age-Friendly City questionnaire of the WHO.

Results: Findings showed that the outdoor spaces and buildings indicator mean= 39.70 (the item of access to mosques and religious places has the highest mean (3.84), the housing indicator) mean $=7.80$ (the item of proportion of the elderly house with its needs has the highest mean (3.15), the transportation indicator (mean $=34.80$ ) the item of existence of bus route to key destinations in the city and public centers with the highest mean (3.42) and the health services indicator (mean $=22.80$ ) the item of access to elderly health insurance services has the highest mean (2.70).

Conclusion: Considering the situation of the health services indicator compared to other indicators it can be said that the city of Tehran has not had favorable conditions in this indicator. Therefore, it is suggested that due to the upward trend of the country's elderly population, health policy makers and urban planners should consider improving the quality of health services indicators for the elderly in Tehran as a priority.

Keywords: Age Friendly City, Outdoor Spaces and Buildings, Transportation, Housing, Community Support and Health Services

Paper Type: Research Article.

Citation (Vancouver): Estebsari F, Rahimi Khalifeh Kandi Z, Nasiri M, Moradi Fath M, Karimi Yeganeh F, Mostafaei D. Evaluation of Transportation Infrastructure and Urban Space of Tehran based on The Indicators of Age Friendly City. Iran J Health Educ Health Promot. Summer 2021;9(2):187-200.

- Citation (APA): Estebsari F., Rahimi Khalifeh Kandi Z., Nasiri M., Moradi Fath M., Karimi Yeganeh F., Mostafaei D. (Summer 2021). Evaluation of Transportation Infrastructure and Urban Space of Tehran based on The Indicators of Age Friendly City. Iranian Journal of Health Education \& Health Promotion., 9(2), 187-200. 


\title{
ارزبابى زيرساختهاى حملونقل و فضاى شهرى تهران بر اساس شاخصهاى
}

\author{
شهردوستدارسالمند
}

\section{0 -}

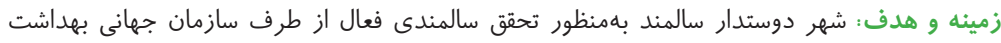

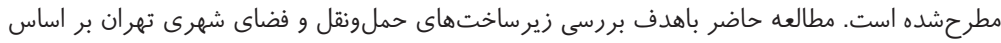

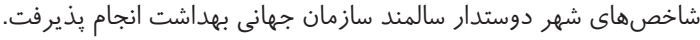

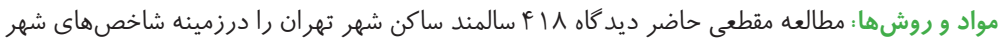

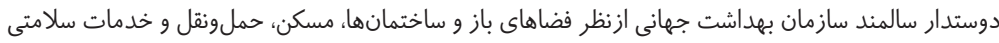

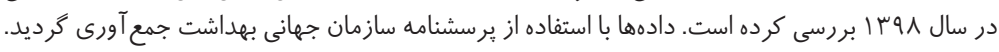

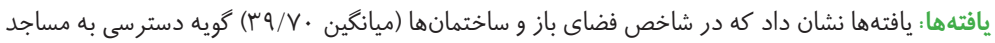

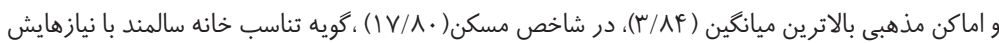

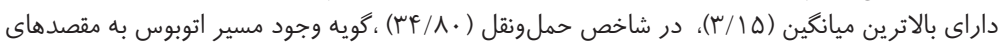

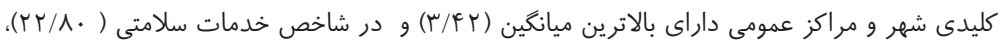

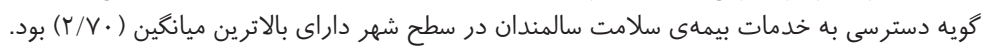

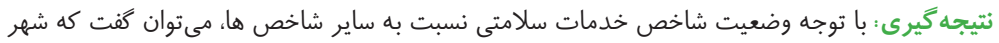

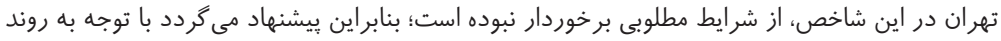

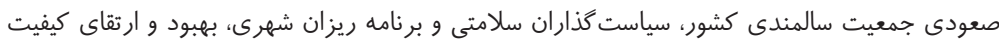

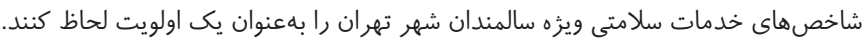

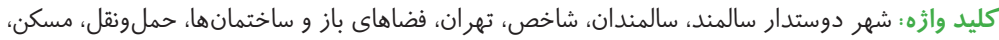

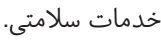
نوع مقاله : مطالعه :خزوهشى.

4 استناد (ونكوور): استبصارى ف، رحيمى خليفه كندى ز، نصيرى م، مرادى فتح م، كرئ كريمى يكانه ف،

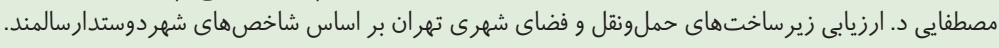

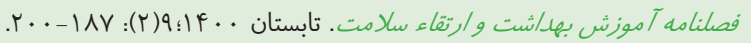

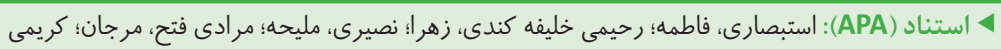

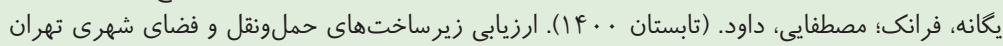

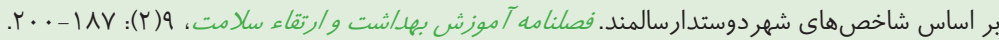

دكتراى آموزش بهداشت و ارتقاى سلامت، استاديار،

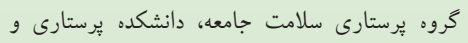

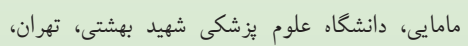

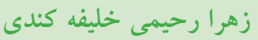

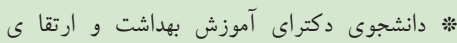

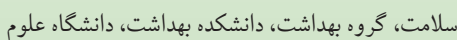

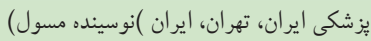
tarla1367@yahoo.com

مليحه نصيرى

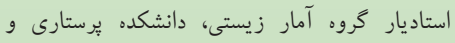

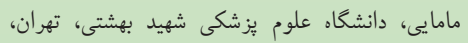

مرجان مرادى فتح

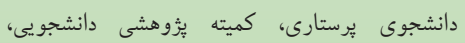
دانشكاء علوم يزشكى شهيد بهشتى، تهران، ايران فر انكى كريمى يُخانه

كارشناس ارشد جمعيت شناسى ، شبكه بهداشتى ازنا ، دانشكاء علوم يزشكى لرستان ، لرستان ، ايران. داود مصطفايى دانيكان علوم ينكي دكتراى مديريت خدمات بهداشتى، دانشكاء. علوم يزشكى شهيد بهشتى، تهران، ايران.

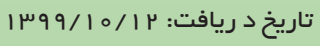

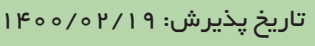


بيشتر ديدهشده است (1) (1). بر اساس نتايج آخرين سرشمارى ايران

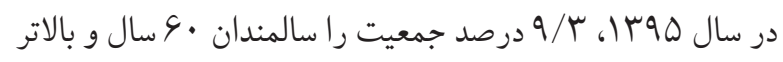
تشكيل مىدادند (^). مسئلهى سالمندى جمعيت ايران به دلايل

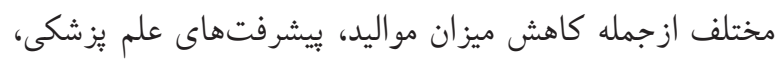

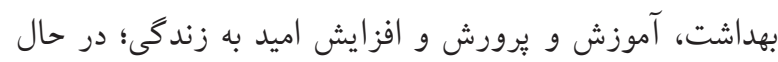

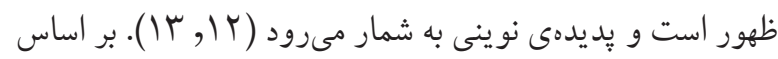

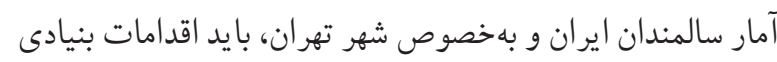
و ضرورى براى مقابله با اين تغيير جمعيتى انجام شود و شرايط ليط

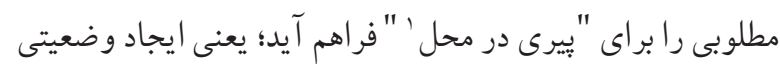

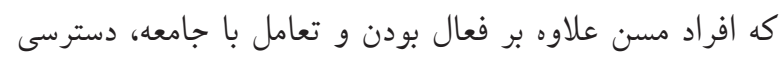

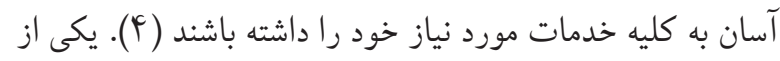

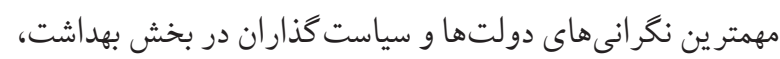
ارتقاى سلامت كروههاى مختلف جامعه ازجمله سلامت سالمندان مى باشد. در مفهوم ارتقاى سلامت، توجه به همه جنبهاى سلام سلامتى

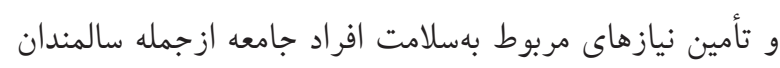

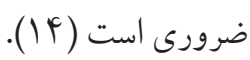
يكى از راهكارهاى ارائه شده براى تأمين نيازهاى شناخته شده

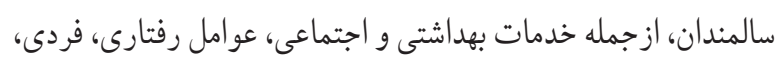

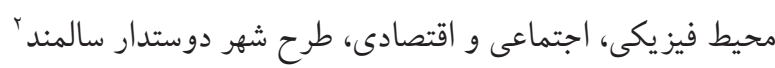

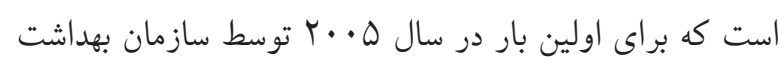

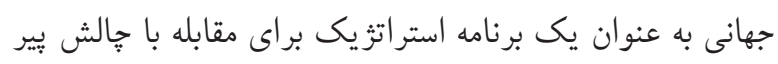

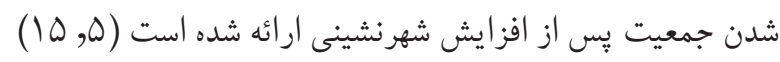

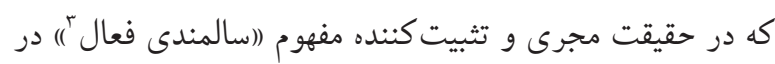

$$
\text { جوامع است (IV, (I) - (1). }
$$

سالمندى فعال به عنوان يك اصطلاح رايج، فر اهم كننده سلامت،

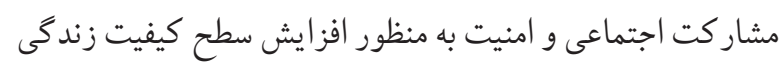

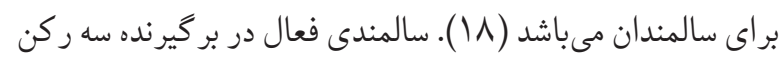

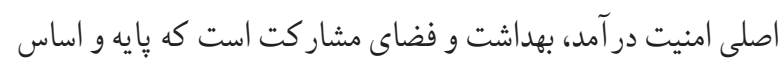

1. Ageing in place

2. Age-Friendly Cities

3. Ageing Active
جمعيت جهان بهسرعت در حال بير شدن است و پيبرى جمعيت

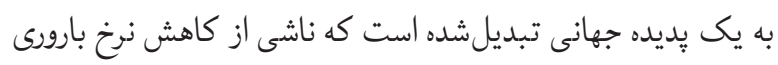

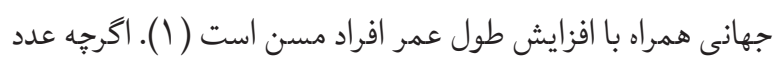
مشخصى براى سن بيرى مشخص نشده است، اما سازمان ملل متحد

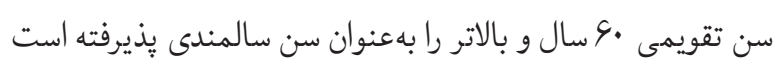

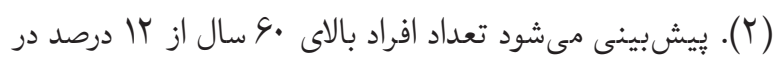

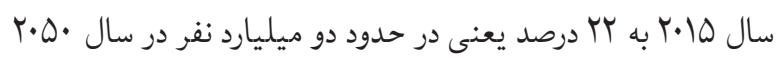

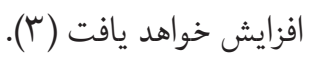
آمارها حاكى از كاهش حداكثر ميزان إنان بارورى در بين كشورهاى

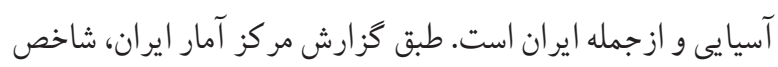

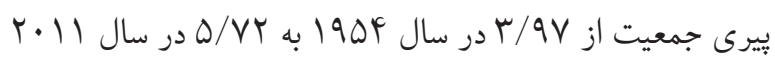

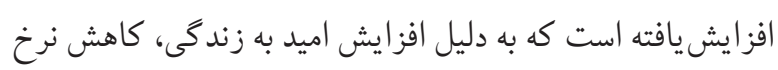

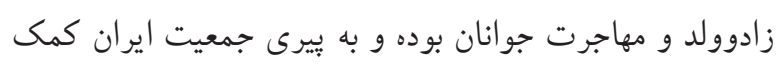

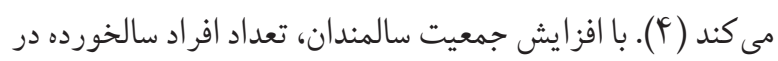

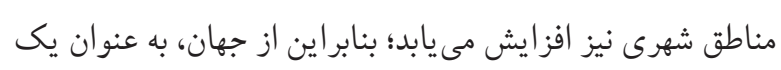

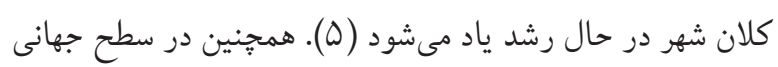

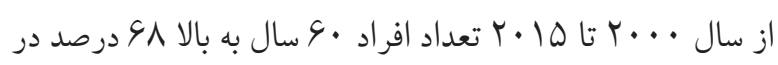
مناطق شهرى و ها درصد در مناطق روستايى افزايش يافته است (9).

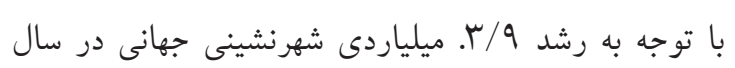

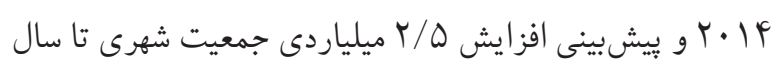

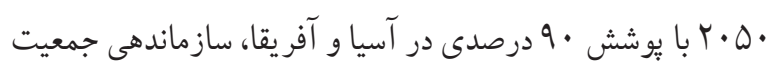

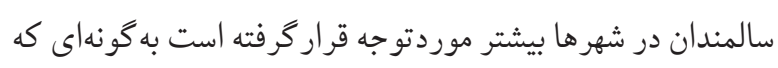
موضوع سالمندى و شهرنشينى بيشتر تأكيد شده است (V) (V). ايران

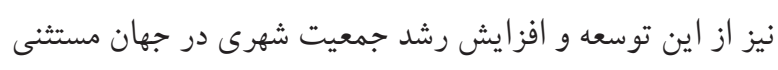

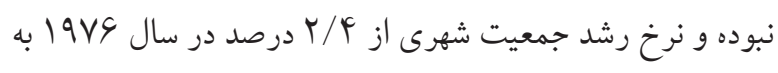

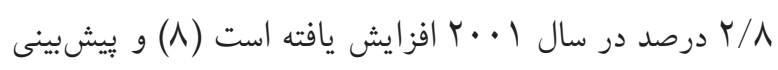

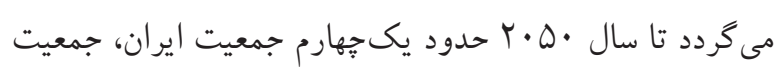

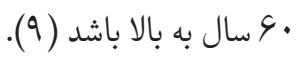

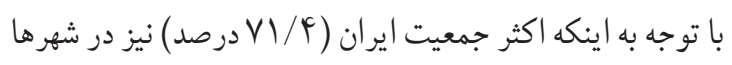

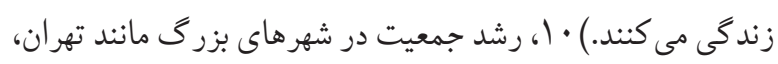


شاخصهاى شهر دوستدار سالمند بر اساس معيار هاى شهر سازى

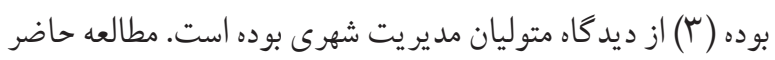
با هدف بررسى وضعيت شهر تهران از نظر شاخصهاى دوستدار سالمند سازمان جهانى بهداشت طر احى گرديد. در اين مطالعه، ديدگًاه

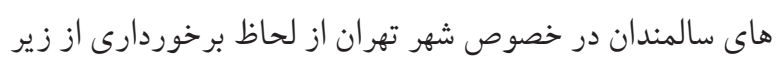
ساخت هاى حمل و نقل و فضاى شهرى مثل شاخص فضاهاى باز

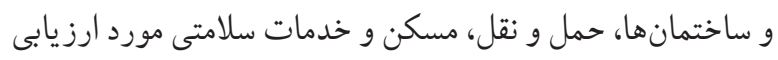

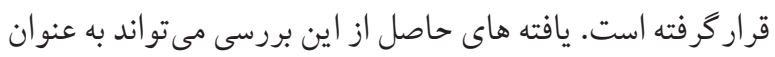

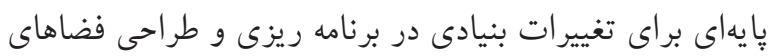

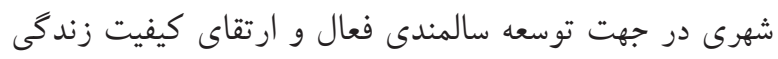
سالمندان جامعه مورداستفاده قرار گيرد.

$$
\text { مو اد و روش ها }
$$

نوع مطالعه: يُوهش حاضر يك مطالعه توصيفى- مقطعى مى باشد

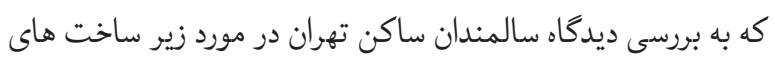
حمل و نقل و فضاى شهرى تهران بر اساس شاخص هاى شهر دوستدار سالمند در سال \وسا پِرداخته است.

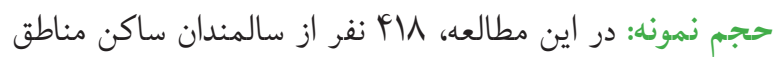

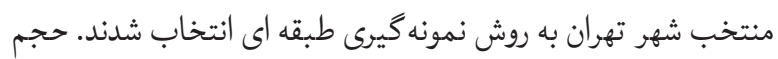

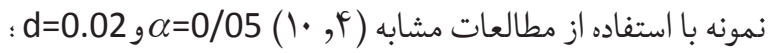
$n=\frac{Z_{1-\alpha / 2}{ }^{2} S^{2}}{d^{2}} \approx 418$

$$
\text { تنعداد } S=(R / 6)=0.66
$$

روش نمونه گَيرى: در اين بزّوهش نمونه گيرى طبقهايى انجام شد،

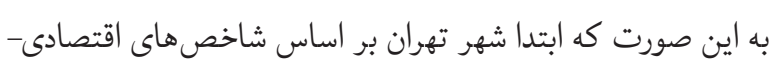

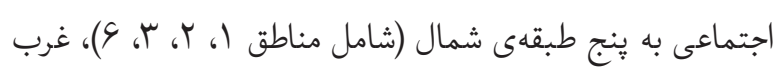

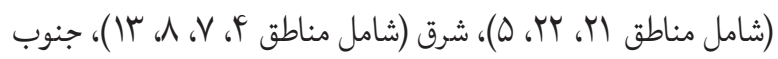

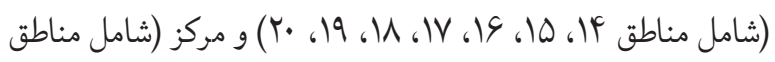

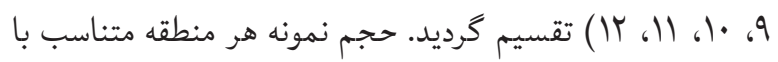

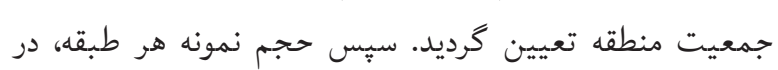
يارك هايى كه محل تجمع سالمندان بوده شناسايى و انتخاب شدند. نمونها به صورت تصادفى ساده و بر اساس فرد بودن شماره
شكل گيرى يك شهر دوستدار سالمند هستند (19 ). سازمان جهانى بهداشت (WHO) هشت حوزه شامل فضاهاى باز و ساختمانها'،

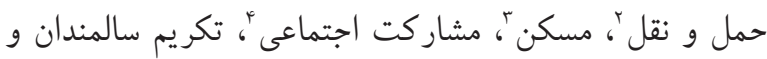

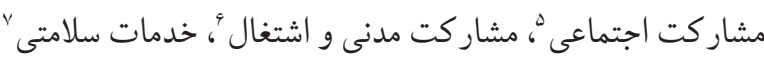

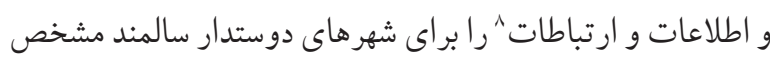

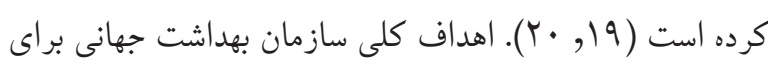

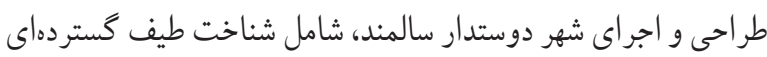

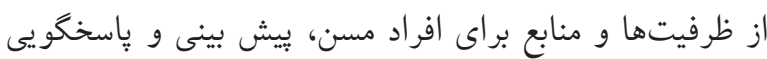

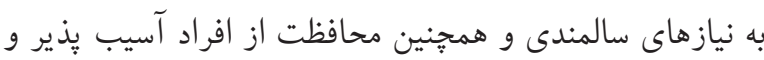

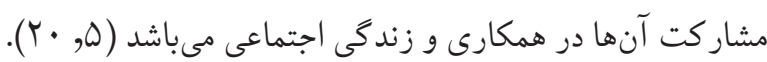
يس از انجام بررسىهاى ميدانى از نقاط مختلف جهان، سرانجام

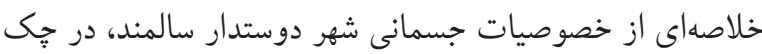

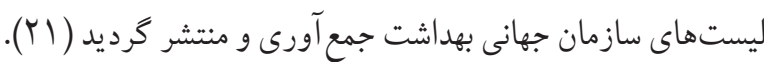

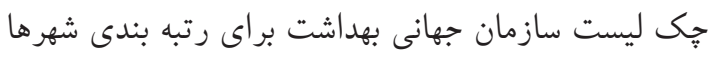

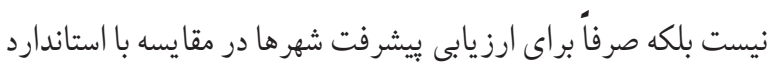

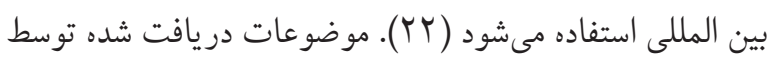

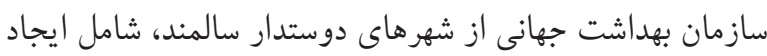
محيط تميز و دليذير، فضاى سبز، مكانهايى براى استراحت، يِياده

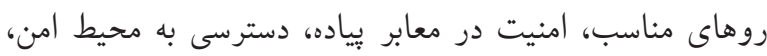

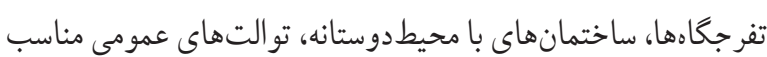

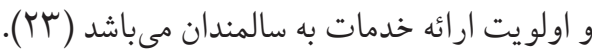
شهر تهران به عنوان پايتخت و يكى از كلان شهرهاى ايران،

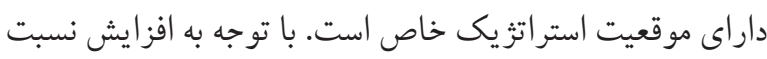
سالمندى در آن موضوع ارتقاى كيفيت زندگى سالمندان به عنوان كروه هاى آسيب بذير، مورد توجه برنامه ريزان و سياست كذاران

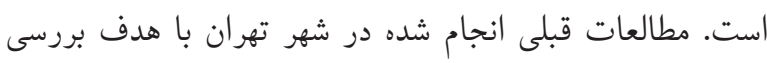

1. Outdoor Spaces and Buildings

2. Transportation

3. Housing

4. Social Participation

5. Respect and Social Inclusion

6. Civic-Participation and Employment

7. Community Support and Health Services

8. Communication and Information 


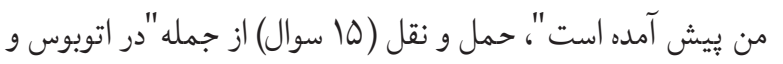
مترو صندلى هاى ويثزه سالمندان وجود دارد و اولويت نشستن رعايت مىشود" و خدمات سلامتى (•ال سوال) از جمله "در مورد مراكز

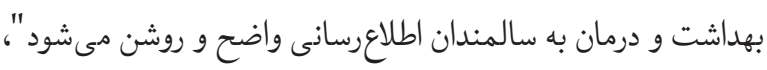
از مجموعه شاخصهاى مورد ارزيابى قرار گرفت.

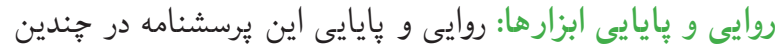
مطالعه در ايران سنجيده شده و مورد تاييد قرار گرفته است ( •ا,

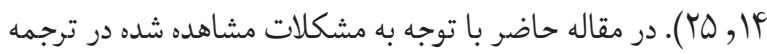

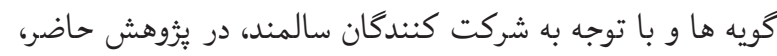

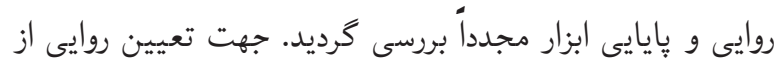

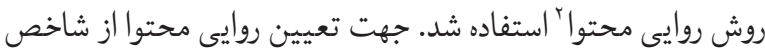
روايى محتوا و نسبت روايى محتوا (CVR\&CVI) استفاده مىشود.

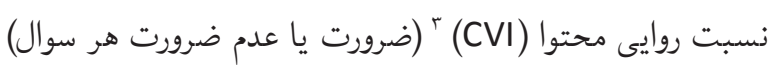

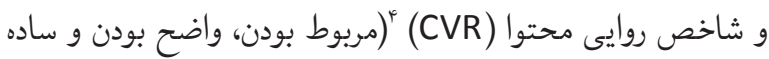
بودن هر سوال) را مورد بررسى قرار مى دهد. به منظور بررسى اين

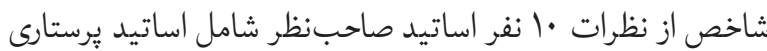

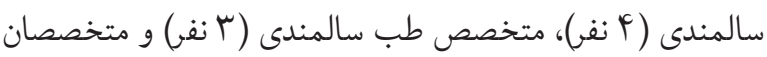

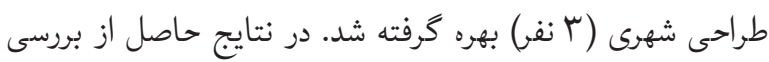

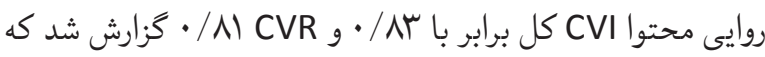

$$
\text { قابل قبول هستند. }
$$

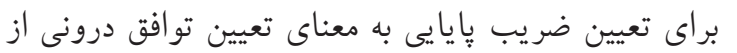

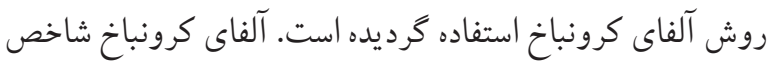

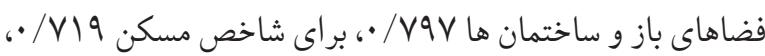

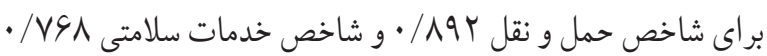

$$
\text { به دست آمد. }
$$

براى تجزيه و تحليل داده ها از نرم افزار SPSS نسخه 1 إمله

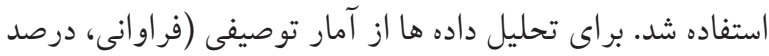
فراوانى، ميانخين و انحر اف معيار ) استفاده شد.

2. Content validity

3. Content validity index

4. Content validity ratio

معيار هاى ورود: معيارها شامل سن •9 سال و بالاتر، ساكن شهر تهران، تسلط به زبان فارسى، توانايى ڤِاسخگويى به سوالات و تمايل شركت در مطالعه بود. ملاحظات اخلاقى: مطالعه حاضر حاصل طرح يُوهشى مصوب

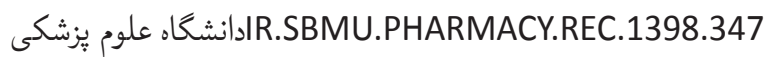
شهيد بهشتى مى باشد. يرسشنامه بىنام بوده و هدف از يزوهش براى

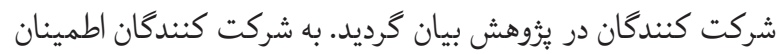
داده شد كه اطلاعات محرمانه بوده و فقط براى اهداف يزوهش استفاده خواهد شد و نتايج آنها بهصورت كلى منتشر خواهد شد. قبل از داز تكميل برسشنامه رضايت نامه كتبى از شركت كنندگان در يُوهش

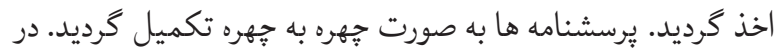
صورتى كه سالمند خود قادر به تكميل برسشنامه نبوده، از كمك جرد يثزوهشكر استفاده كرديد. ابزار گَردآورى دادهها: ابزار گردآورى دادهها در اين مطالعه، شامل يرسشنامهى اطلاعات دموگرافيكى و يرسشنامه ارزيابى شاخصهاى

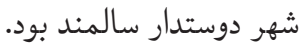
يُرسشنامه دموكرافيكى: شامل سن، جنس، وضعيت تأهل، تحصيلات، مدت زمان سكونت در تهران، نوع مالكيت مسكن، وضعيت اشتغال، درآمد، زندكى با جه كسى، بيمه درمانى، وضعيت سلامتى فرد، ابتلا

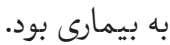

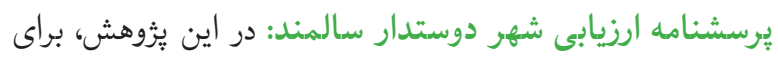

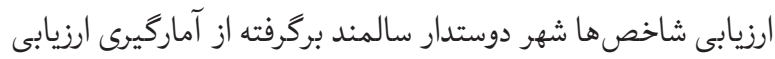

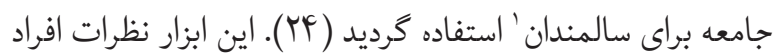
شركت كننده در مطالعه در يك مقياس ينج قسمتى كاملا مخالفم

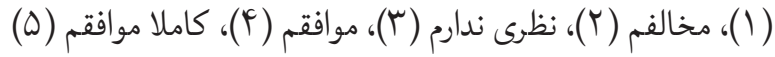
مى سنجد. با توجه به اهداف مطالعه به منظور بررسى زيرساخت هاى

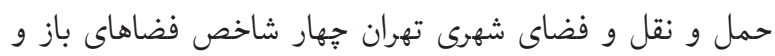

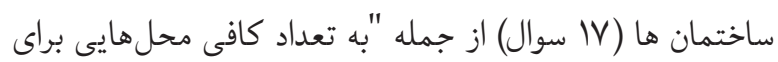

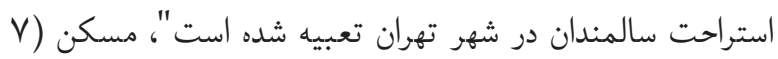

1. Community Assessment Survey for Older Adults(CASOA) 


\begin{tabular}{|c|c|c|c|}
\hline$\Delta \cdot / V$ & rrV & بازنشسته & \multirow{5}{*}{ وضعيت اشتغال } \\
\hline$q / 4$ & pr & كار تمام وقت & \\
\hline $9 / 1$ & pq & كار ياره وقت & \\
\hline $\mathrm{V} / \mathrm{\Lambda}$ & ro & بيكار & \\
\hline rT/ & $1 \cdots$ & ساير & \\
\hline$\Delta V / l$ & TFS & بله & \multirow{2}{*}{ كفايت در آمد } \\
\hline ET/A & $19 r$ & خير & \\
\hline$F \mid / 0$ & IVS & با همسر & \multirow{5}{*}{ باجه كسى زحال حاضر } \\
\hline Tr/s & Ifs & با همسر و فرزندان & \\
\hline $11 / 9$ & $\Delta r$ & با فرزندان & \\
\hline $9 / 9$ & pr & تنهها & \\
\hline$F / V$ & rl & ساير موارد & \\
\hline$r q / \Delta$ & IVV & خوب & \multirow{3}{*}{ وضعيت سلامت : } \\
\hline$\Delta \cdot / V$ & rtr & متوسط & \\
\hline $9 / 1$ & pq & ضعيف & \\
\hline$\Lambda F / S$ & rvq & بله & \multirow{2}{*}{ بيمه درمانى } \\
\hline $\mid \Delta / f$ & 99 & خير & \\
\hline Ts/s & 194 & بله & \multirow{2}{*}{ بيمارى مزمن } \\
\hline s & rAF & خير & \\
\hline
\end{tabular}

جدول Y شاخص فضاهاى باز و ساختمانها را به تفكيك هر سوال نشان مىدهد، همحِنين در اين شاخص، "دسترسى به مساجد و اماكن

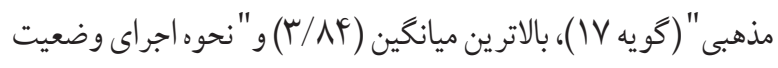

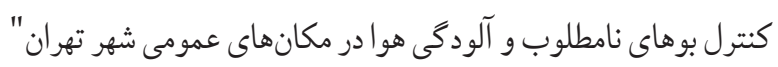

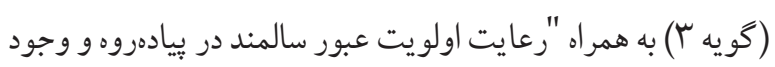

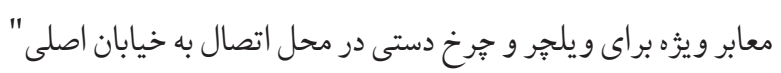

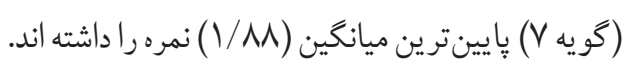

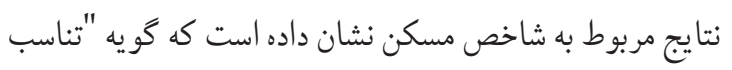
خانه سالمند با نيازهاى وى " (كويه ץ) داراى بالاترين ميانگين

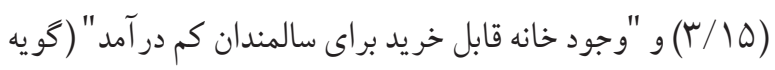

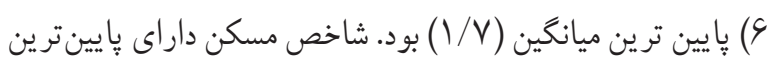

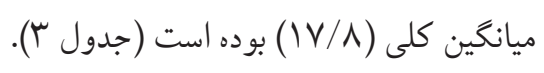

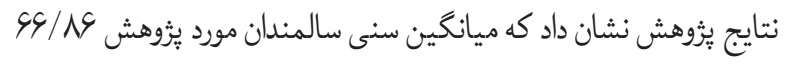

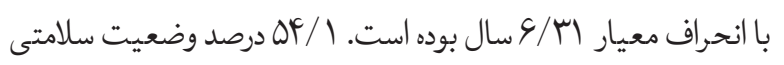

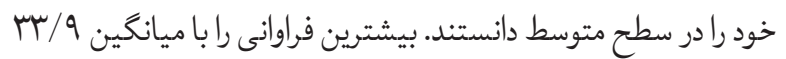
درصد مربوط به تحصيلات دييلم و كمترين فراوانى با ميانكين 9 /. درصد مربوط سطح تحصبلات بىسواد بود. I/ 9N درصد سالمندان متاهل

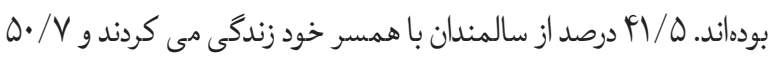

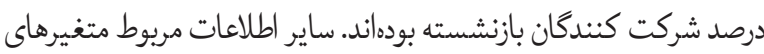
دموكرافيكى در جدول (1) قابل رويت مى باشد. جدول ا. توزيع فراوانى متغيرهاى دموكَرافيك سالمندان شركت

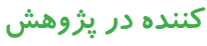

\begin{tabular}{|c|c|c|c|}
\hline درصد & تعداد & متغير & \\
\hline$\Delta r / \Delta$ & rus & مرد & \multirow{2}{*}{ جنسيت } \\
\hline$F V / \Delta$ & سוr & زن & \\
\hline $\mid r / f$ & s. & مجرد & \multirow{4}{*}{ وضعيت تاهل } \\
\hline $9 \wedge / 1$ & 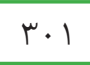 & متاهل & \\
\hline$r / q$ & r & مطلقه & \\
\hline $10 / 9$ & $\checkmark \cdot$ & بيوه & \\
\hline $1 \cdot / 9$ & pq & بيسواد & \multirow{5}{*}{ تحصيلات } \\
\hline $\mid N / \mu$ & Ar & ابتدايى & \\
\hline $10 / r$ & $9 \wedge$ & راهنمايى & \\
\hline - & IOr & متوسطه & \\
\hline$r l / V$ & $9 V$ & دانشگاهى & \\
\hline$\wedge$ & rs & بين ا تا ه سال & \multirow{4}{*}{ تدرت سكونت در } \\
\hline $9 / 0$ & rq & بين צ تا • ال سال & \\
\hline $11 / r$ & $\Delta \cdot$ & بين l| تا •r سال & \\
\hline$V \cdot / r$ & Mll & بيشتراز · r سال & \\
\hline$V r / r$ & TrA & شخصى & \multirow{6}{*}{ نوع مالكيت } \\
\hline $1 \mathrm{~V} / \mathrm{s}$ & $\vee q$ & استيجارى & \\
\hline 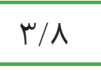 & IV & سازمانى & \\
\hline$r / r$ & 19 & خانه فرزندان & \\
\hline$\cdot / V$ & r & خانه اقوام و آشنايان & \\
\hline$\cdot / 4$ & $r$ & ساير موارد & \\
\hline
\end{tabular}


جدول r. اطلاعات توصيفى شاخص فضاهاى باز و ساختمانها شهر تهران به تفكيك سوالات از ديدگًاه سالمندان شركت كننده در يُوهش

\begin{tabular}{|c|c|c|c|c|c|c|}
\hline \multirow{2}{*}{ (انحراف معيار) } & \multicolumn{5}{|c|}{ تعداد (درصد) } & \multirow[b]{2}{*}{ فضاهاى باز و ساختمانها } \\
\hline & 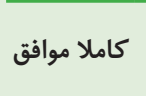 & موافق & بدون نظر & مخالف & 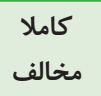 & \\
\hline $\begin{array}{l}r / r r \\
(1 / r V)\end{array}$ & $\begin{array}{ll}1 f \\
(\mu / \mu)\end{array}$ & $\begin{array}{l}9 F \\
(r T / \Delta)\end{array}$ & $\begin{array}{l}\mathrm{rr} \\
(\mathrm{V} / \mathrm{V})\end{array}$ & $\begin{array}{l}11 \\
(r \varepsilon / \mu)\end{array}$ & $\begin{array}{l}19 \Lambda \\
(\mathcal{F} \cdot / r)\end{array}$ & 1 - محيط شهر تهران دلِذير و تميز است. \\
\hline $\begin{array}{l}1 / 91 \\
(1 / \cdot 1)\end{array}$ & $\begin{array}{l}V \\
(1 / V)\end{array}$ & $\begin{array}{l}\Delta r \\
(\mid r / F)\end{array}$ & $\begin{array}{l}\text { rr } \\
(\mathrm{V} / \mathrm{V})\end{array}$ & 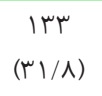 & $\begin{array}{l}19 f \\
(f \& / F)\end{array}$ & r- وضعيت كنترل سر و صدا در مكانهاى عمومى شهر تهران به خوبى اجرا \\
\hline $\begin{array}{l}1 / \wedge \Lambda \\
(1 / \cdot \vee)\end{array}$ & $\begin{array}{c}r \\
(\cdot / V)\end{array}$ & $\begin{array}{l}\Delta s \\
(\mid r / F)\end{array}$ & $\begin{array}{l}\text { re } \\
(\Lambda / 1)\end{array}$ & $\begin{array}{l}|r| \\
(r N / q)\end{array}$ & $\begin{array}{l}r \cdot r \\
(r \wedge / \Lambda)\end{array}$ & r- وضعيت كنترل بوهاى نامطلوب و آلودگى هوا در مكانهاى عمومى شهر \\
\hline $\begin{array}{l}r / Y q \\
(1 / T F)\end{array}$ & $\begin{array}{ll}1 \uparrow \\
(\mu / \mu)\end{array}$ & $\begin{array}{c}\wedge \varsigma \\
(r \cdot / 4)\end{array}$ & $\begin{array}{l}G r \\
(\mid r / \Lambda)\end{array}$ & $\begin{array}{l}1 \cdot F \\
(r F / q)\end{array}$ & $\begin{array}{l}1 \Delta r \\
(r s / F)\end{array}$ & F- به تعداد كافى محلهايى براى استراحت سالمندان در شهر تهران تعبيه \\
\hline $\begin{array}{l}r / \Lambda \Lambda \\
(1 / \mu \Delta)\end{array}$ & $\begin{array}{l}r \mu \\
(V / q)\end{array}$ & $\begin{array}{l}194 \\
(\Psi q / \tau)\end{array}$ & $\begin{array}{l}\text { qr } \\
(1 \cdot / \cdot)\end{array}$ & $\begin{array}{l}\wedge . \\
(19 / 1)\end{array}$ & $\begin{array}{c}99 \\
(Y M / V)\end{array}$ & ه- در فضاهاى سبز به خصوص در يار كىها مكانهاى مسقف و سايهدار به و ايمن وجنه دارد. \\
\hline
\end{tabular}

\begin{tabular}{|c|c|c|c|c|c|c|}
\hline $\begin{array}{l}r / \Delta 1 \\
(1 / \mu F)\end{array}$ & $\begin{array}{l}r r^{\prime} \\
(\Delta / \cdot)\end{array}$ & $\begin{array}{l}1,4 s \\
(r \cdot / 1)\end{array}$ & $\begin{array}{l}\text { rs } \\
(\Lambda / G)\end{array}$ & $\begin{array}{l}91 \\
(r \mu / \mathcal{F})\end{array}$ & 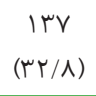 & 4- در ايستغاههاى حمل و نقل عمومى محيط و على الخصوص صندلىهاى \\
\hline $\begin{array}{l}1 / \wedge \Lambda \\
(1 / \cdot \Delta)\end{array}$ & $\begin{array}{c}\Delta \\
(1 / Y)\end{array}$ & $\begin{array}{l}F V \\
(11 / r)\end{array}$ & $\stackrel{\mu \wedge}{(9 / 1)}$ & $\begin{array}{l}(r \mid \mu) \\
(\mu / / \Lambda)\end{array}$ & $\begin{array}{l}190 \\
(f s / V)\end{array}$ & 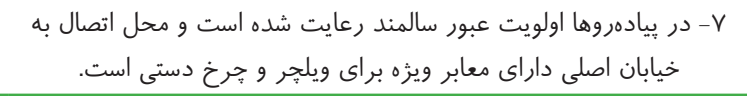 \\
\hline $\begin{array}{l}r / T Y \\
(1 / r \varphi)\end{array}$ & $\begin{array}{l}1 F \\
(\mu / \mu)\end{array}$ & $\begin{array}{l}91 \\
(r \mu / \mathcal{F})\end{array}$ & $\begin{array}{l}01 \\
(I Y / Y)\end{array}$ & $\begin{array}{l}1 \cdot 9 \\
(r s / 1)\end{array}$ & $\begin{array}{l}\text { lfs } \\
(\mu F / q)\end{array}$ & 1- در شهر به ميزان كافى توالت عمومى با امكانات و بهداشت مناسب \\
\hline $\begin{array}{l}1 / 99 \\
(1 / 11)\end{array}$ & $\begin{array}{l}1 \mu \\
(r / 1)\end{array}$ & $\begin{array}{l}\Delta q \\
(1 q / 1)\end{array}$ & $\begin{array}{l}r \cdot \\
(V / r)\end{array}$ & $\begin{array}{l}110 \\
(r V / 0)\end{array}$ & $\begin{array}{l}r \cdot 1 \\
(r \wedge / 1)\end{array}$ & 9- در توالتهاى عمومى، توالت مناسب براى سالمندان (توالت فرنگى) تعبيه \\
\hline $\begin{array}{l}r / r \\
(1 / 1 r)\end{array}$ & $\begin{array}{c}0 \\
(1 / Y)\end{array}$ & $\begin{array}{c}s \mathcal{F} \\
(1 \Delta / \mu)\end{array}$ & $\begin{array}{l}4 q \\
(11 / V)\end{array}$ & $\begin{array}{l}|r| \\
(r N / 9)\end{array}$ & $\begin{array}{l}\operatorname{lvq} \\
(\mathcal{E} Y / \Lambda)\end{array}$ & 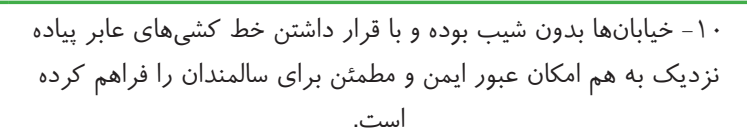 \\
\hline
\end{tabular}

\begin{tabular}{|c|c|c|c|c|c|c|}
\hline $\begin{array}{l}r / 19 \\
(1 / r r)\end{array}$ & $\begin{array}{c}r \cdot \\
(r / \Lambda)\end{array}$ & $\begin{array}{c}g f \\
(1 \Delta / \mu)\end{array}$ & $\begin{array}{c}\Delta r \\
(1 r / V)\end{array}$ & $\begin{array}{c}\mid r r \\
(r q / F)\end{array}$ & $\begin{array}{c}\mid \Delta \wedge \\
(r \mathrm{r} / \Lambda)\end{array}$ & 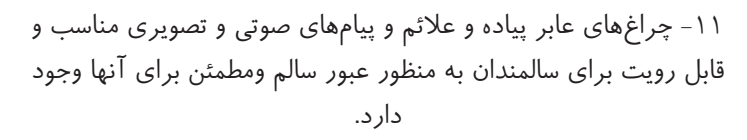 \\
\hline $\begin{array}{l}1 / 91 \\
(1 / .9)\end{array}$ & $\begin{array}{c}9 \\
(r / r)\end{array}$ & $\begin{array}{c}\Delta \cdot \\
(\mid r / \cdot)\end{array}$ & $\begin{array}{c}r f \\
(1 \cdot / 0)\end{array}$ & $\begin{array}{c}\text { Irv } \\
(r r / \wedge)\end{array}$ & $\begin{array}{l}\mid \vee \wedge \\
(F r / s)\end{array}$ & 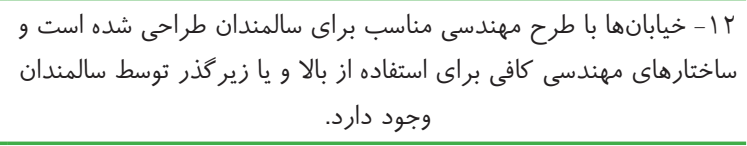 \\
\hline $\begin{array}{l}r / Y F \\
(1 / Y I)\end{array}$ & $\begin{array}{c}1 r \\
(r / 1)\end{array}$ & $\begin{array}{c}11 \\
(19 / F)\end{array}$ & $\begin{array}{c}\Delta r \\
(\mid r / F)\end{array}$ & $\begin{array}{c}1 r r \\
(r q / r)\end{array}$ & $\begin{array}{c}10 . \\
(10 / q)\end{array}$ & 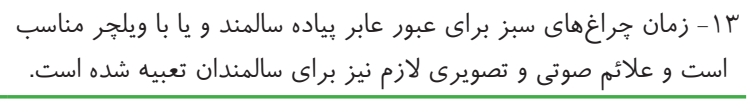 \\
\hline $\begin{array}{l}r / r r \\
(1 / 1 \Lambda)\end{array}$ & $\begin{array}{l}1 \\
(r / F)\end{array}$ & $\begin{array}{l}V V \\
(\mid \Lambda / f)\end{array}$ & $\Delta \wedge$ & $\begin{array}{l}\mid r r \\
(r q / F)\end{array}$ & $\begin{array}{l}10 . \\
(r \Delta / 9)\end{array}$ & fl أ - محلهاى توقف تاكسى و اتوبوس مناسب سالمندان است. \\
\hline $\begin{array}{l}r / V V \\
(1 / \mu l)\end{array}$ & $\begin{array}{l}r q \\
(\varsigma / 9)\end{array}$ & $\begin{array}{l}(r r / \Lambda) \\
\text { lur }\end{array}$ & $\begin{array}{l}s \mu \\
(10 / 1)\end{array}$ & $\begin{array}{c}\wedge 9 \\
(r / / \mu)\end{array}$ & $\begin{array}{l}1 \cdots \\
(r \mu / q)\end{array}$ & ها - ورودى پار كها براى ويلجر و جرخ دستى و غيره مناسب است. \\
\hline $\begin{array}{l}r / 9 \Lambda \\
(1 / r \Delta)\end{array}$ & $\begin{array}{l}r F \\
(\Delta / V)\end{array}$ & $\begin{array}{l}11 \mathrm{~V} \\
(\mathrm{rN} / \cdot)\end{array}$ & $\begin{array}{l}V Q \\
(1 V / 9)\end{array}$ & $\begin{array}{c}1 . \varphi \\
(r \Delta / f)\end{array}$ & $\begin{array}{c}98 \\
(r \mu / \cdot)\end{array}$ & 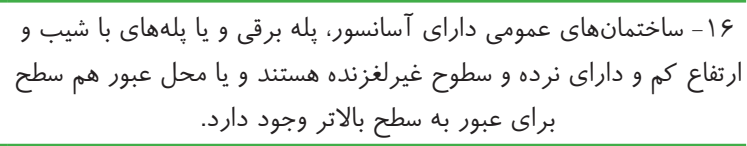 \\
\hline $\begin{array}{l}r / \wedge f \\
(1 / r \Delta)\end{array}$ & $\begin{array}{c}10 \mathrm{~V} \\
(\mathrm{r} V / \varepsilon)\end{array}$ & $\begin{array}{c}\mid F r \\
(\mu F / \mu)\end{array}$ & $\begin{array}{c}q V \\
(11 / \mu)\end{array}$ & $\begin{array}{c}\mu F \\
(\Lambda / r)\end{array}$ & $\begin{array}{c}\mu \varsigma \\
(\Lambda / \varphi)\end{array}$ & IV - در محله ى سكونت دستر سى به مساجد و اماكن مذهبى وجود دارد. \\
\hline \multicolumn{6}{|c|}{$(11 / \Delta) r q / \vee$} & ميانكين كل(انحر اف معيار) شاخص فضاهاى باز و ساختمانها \\
\hline
\end{tabular}


جدول ب. اطلاعات توصيفى شاخص مسكن شهر تهران به تفكيك سو الات از ديدكاه سالمندان شركت كننده در يُزوهش

\begin{tabular}{|c|c|c|c|c|c|c|}
\hline \multirow{2}{*}{ (انحراف معيار) } & \multicolumn{5}{|c|}{ تعداد (درصد) } & \multirow[b]{2}{*}{ 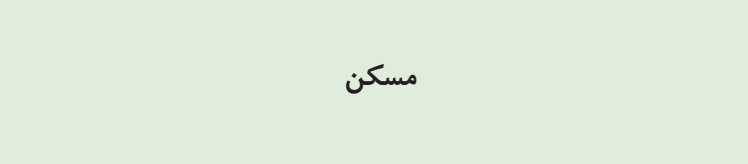 } \\
\hline & كواملا & 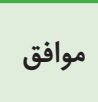 & 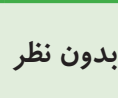 & 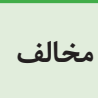 & مخالف & \\
\hline $\begin{array}{l}r / \Psi V \\
(1 / r \Delta)\end{array}$ & $\begin{array}{l}\text { ro } \\
\text { (s) }\end{array}$ & $\begin{array}{c}q V \\
(r r / r)\end{array}$ & $\begin{array}{l}\text { is } \\
(11)\end{array}$ & $\begin{array}{c}q . \\
(r / / \Delta)\end{array}$ & $\begin{array}{c}19 . \\
(\mu / / \mu)\end{array}$ & 1 - توانايى خريد مسكن در تهران را دارم. \\
\hline $\begin{array}{l}r / V I \\
(1 / / r)\end{array}$ & $\begin{array}{c}4 q \\
(11 / V)\end{array}$ & $\begin{array}{c}99 \\
(r \mu / V)\end{array}$ & $\begin{array}{c}q . \\
(\mid F / F)\end{array}$ & $\begin{array}{c}1.1 \\
(r F / r)\end{array}$ & $\begin{array}{c}1 \cdot \wedge \\
(r \Delta / \wedge)\end{array}$ & r - تنوع در انتخاب نوع مسكن وجود دارد. \\
\hline $\begin{array}{l}\mu / 10 \\
(1 / \mu F)\end{array}$ & $\begin{array}{c}41 \\
(\mid f / 4)\end{array}$ & $\begin{array}{c}19 . \\
\left(\mu^{\prime} / / \mu\right)\end{array}$ & $\begin{array}{c}01 \\
(\mid Y / Y)\end{array}$ & $\begin{array}{c}V^{\mu} \\
(I V / \Delta)\end{array}$ & $\begin{array}{c}V^{\mu} \\
(\mid V / Q)\end{array}$ & بـ- خانهى من مناسب نيازهاى من است. \\
\hline $\begin{array}{l}\mu / \cdot \wedge \\
(1 / \mu 1)\end{array}$ & $\begin{array}{c}\mu q \\
(q / \mu)\end{array}$ & $\begin{array}{c}\text { IAr } \\
(F r / \Delta)\end{array}$ & $\begin{array}{l}\Delta \cdot \\
(I r)\end{array}$ & $\begin{array}{c}9 \wedge \\
(\mid s / \mu)\end{array}$ & $\begin{array}{c}V q \\
(1 N / 9)\end{array}$ & 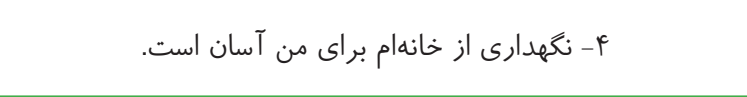 \\
\hline $\begin{array}{l}r / \Delta 1 \\
(1 / r V)\end{array}$ & $\begin{array}{c}\mu r \\
(V / Y)\end{array}$ & $\begin{array}{c}V \wedge \\
(\mid \Lambda / V)\end{array}$ & $\begin{array}{c}V Y \\
(I V / r)\end{array}$ & $\begin{array}{l}I F F \\
(r q / V)\end{array}$ & $\begin{array}{c}\| r \\
(r \& / \Lambda)\end{array}$ & ه- مشكل افتادن و صدمه زدن به خود در منزل براى من بيش آمده \\
\hline $\begin{array}{l}1 / V \\
(1 / \cdot \Delta)\end{array}$ & $\begin{array}{l}10 \\
(\mu / 4)\end{array}$ & $\begin{array}{l}19 \\
(f / 0)\end{array}$ & $\begin{array}{l}41 \\
(9 / 1)\end{array}$ & $\begin{array}{l}q r \\
(r Y / Q)\end{array}$ & $\begin{array}{l}r \digamma q \\
(\Delta Q / \varsigma)\end{array}$ & צ- براى سالمندان كم در آمد خانهى قابل خريد وجود دارد. \\
\hline $\begin{array}{l}r / F G \\
(1 / \mu r)\end{array}$ & $\begin{array}{l}r \varphi \\
(\varphi / r)\end{array}$ & $\begin{array}{l}90 \\
(r Y / V)\end{array}$ & $\begin{array}{c}9 \wedge \\
(\mid s / \mu)\end{array}$ & $\begin{array}{l}19 \\
(r) / r)\end{array}$ & $\begin{array}{l}1 F \cdot \\
(\mu / \Delta / \Delta)\end{array}$ & V- خانههاى امن و در دسترس وجود دارد. \\
\hline \multicolumn{6}{|c|}{$(\Delta / \Delta) \mid V / \Lambda$} & ميانگين (انحر اف معيار) كل شاخص مسكن \\
\hline
\end{tabular}

در شاخص حمل و نقل (جدول Yl)، كويه "نياز وجود به مسير و اختصاص كارتهاى تخفيف ويزه به آنان" (كو يه V) پايينت ترين

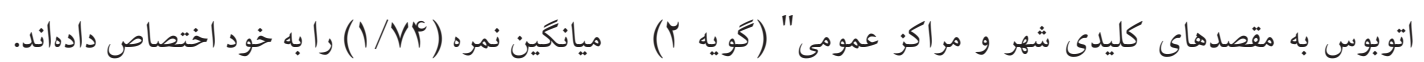

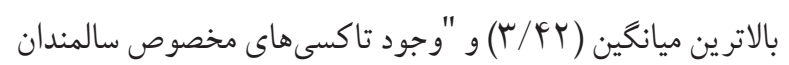

جدول ع. اطلاعات توصيفى شاخص حمل و نقل درون شهرى شهر تهران به تفكيك سوالات از ديدگًاه سالمندان شركت كننده در يزوهش

\begin{tabular}{|c|c|c|c|c|c|c|}
\hline \multirow{2}{*}{ (انحراف معيار) } & \multicolumn{5}{|c|}{ تعداد (درصد) } & \multirow{2}{*}{ حمل و نقل } \\
\hline & 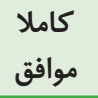 & موافق & بدون نظر & مخالف & 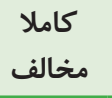 & \\
\hline $\begin{array}{l}r / .9 \\
(1 / r)\end{array}$ & $\begin{array}{l}1 r \\
(r / 9)\end{array}$ & $\begin{array}{l}V Y \\
(I V / r)\end{array}$ & $\begin{array}{l}\text { rs } \\
(\Lambda / q)\end{array}$ & $\begin{array}{l}\operatorname{lr} r \\
(r q / r)\end{array}$ & $\begin{array}{l}\text { IVG } \\
(4 r / 1)\end{array}$ & 1 - تجهيزات مناسب سالمندان در بايانهها و ايستكاههاى حمل و نقل \\
\hline $\begin{array}{l}r / F r \\
(1 / Y I)\end{array}$ & $\begin{array}{l}V Y \\
(I V / r)\end{array}$ & $\begin{array}{l}11 \cdot \\
(\kappa / 1)\end{array}$ & $\begin{array}{l}\Delta q \\
(1 F / 1)\end{array}$ & $\begin{array}{l}9 V \\
(19)\end{array}$ & $\begin{array}{l}r \cdot \\
(q / 4)\end{array}$ & r- مسير اتوبوس به مقصدهاى كليدى شهر و مراكز عمومى مورد نياز \\
\hline $\begin{array}{l}r / \mu r \\
(1 / r \mu)\end{array}$ & $\begin{array}{l}r \cdot \\
(r / \Lambda)\end{array}$ & $\begin{array}{l}V S \\
(\mid N / r)\end{array}$ & $\begin{array}{l}9 \mu \\
(10 / 1)\end{array}$ & $\begin{array}{l}\operatorname{lr} r \\
(r q / r)\end{array}$ & $\begin{array}{l}1 \mu r \\
(r r / \Lambda)\end{array}$ & سـ- در ايستخاه هاى مترو و اتوبوس خدمات مناسب و ويزه به سالمندان \\
\hline $\begin{array}{l}r / Y q \\
\left(1 / Y F^{\prime}\right)\end{array}$ & $\begin{array}{l}19 \\
(r / \Lambda)\end{array}$ & $\begin{array}{l}91 \\
(r) / \Lambda)\end{array}$ & $\begin{array}{l}r \varphi \\
(\Lambda / \varepsilon)\end{array}$ & $\begin{array}{l}\mid \mu r \\
(\mu \mid / \varepsilon)\end{array}$ & $\begin{array}{l}1 F \mu \\
(\mu F / Y)\end{array}$ & ץ- در اتوبوس و مترو صندلى هاى ويزه سالمندان وجود دارد و اولويت \\
\hline $\begin{array}{l}r / \Lambda \\
(1 / r \Delta)\end{array}$ & $\begin{array}{l}r \cdot \\
(r / \Lambda)\end{array}$ & $\begin{array}{l}\mid F \wedge \\
(r \Delta / \Delta)\end{array}$ & $\begin{array}{l}4 \pi \\
(18 / 1)\end{array}$ & $\begin{array}{l}1.1 \\
(Y \Psi / Y)\end{array}$ & $\begin{array}{l}\wedge \Delta \\
(r \cdot / \mathcal{F})\end{array}$ & ه- در تمامى اوقات على الخصوص ساعات بايانى شب وسايل نقليه \\
\hline $\begin{array}{l}1 / 1 \\
(\cdot / 90)\end{array}$ & $\begin{array}{l}4 \\
(1 / \mathbb{F})\end{array}$ & $\begin{array}{l}r V \\
(\varphi / 0)\end{array}$ & $\begin{array}{l}\text { kr } \\
(1 \cdot)\end{array}$ & $\begin{array}{l}14 q \\
(r \Delta / q)\end{array}$ & $\begin{array}{l}19 F \\
(q \varphi / F)\end{array}$ & 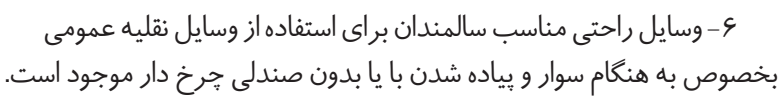 \\
\hline
\end{tabular}




\begin{tabular}{|c|c|c|c|c|c|c|}
\hline $\begin{array}{l}1 / \mathrm{VF} \\
(1 / \cdot 1)\end{array}$ & $\begin{array}{l}1 \cdot \\
(r / \mathcal{T})\end{array}$ & $\begin{array}{l}r \cdot \\
(r / \Lambda)\end{array}$ & $\begin{array}{l}\Delta r \\
(\mid r / F)\end{array}$ & $\begin{array}{l}1 \cdot 9 \\
(r s / 1)\end{array}$ & $\begin{array}{l}r T V \\
(\Delta T / T)\end{array}$ & تخفيف ويزه داده مالمندان وجود دارد و به به آنها كارتهاى \\
\hline $\begin{array}{l}1 / 11 \\
(1 / \cdot 1)\end{array}$ & $\begin{array}{c}4 \\
(1 / \mathcal{F})\end{array}$ & $\begin{array}{l}r F \\
(\Delta / V)\end{array}$ & $\begin{array}{l}V F \\
(I V / V)\end{array}$ & $\begin{array}{c}9 V \\
(r \mu / r)\end{array}$ & $\begin{array}{l}r \mid V \\
(01 / 9)\end{array}$ & ^- ياركينگ هاى مناسب سالمندان در شهر به اندازمى كافى وجود دارد. \\
\hline $\begin{array}{l}r / V V \\
(1 / r \Delta)\end{array}$ & $\begin{array}{l}(\mathrm{V} / \mathrm{V}) \\
\mathrm{m}\end{array}$ & $\begin{array}{l}\text { lfs } \\
(r F / q)\end{array}$ & $\begin{array}{l}\text { rᄉ } \\
(q / 1)\end{array}$ & $\begin{array}{l}91 \\
(r \mu / \mathcal{F})\end{array}$ & $\begin{array}{l}1 \cdot r \\
(r F / 9)\end{array}$ & 9. در خيابانها و بيادهروها نور كافى (بخصوص در شب) وجود دارد. \\
\hline $\begin{array}{l}r / \cdot 9 \\
(1 / 19)\end{array}$ & $\begin{array}{l}1 \cdot \\
(r / \mathcal{F})\end{array}$ & $\begin{array}{l}9 \wedge \\
(19 / \mu)\end{array}$ & $\begin{array}{l}(q) \\
(q / \wedge)\end{array}$ & $\begin{array}{l}\mid r r \\
(r / / 4)\end{array}$ & $\begin{array}{l}19 V \\
(F \cdot)\end{array}$ & 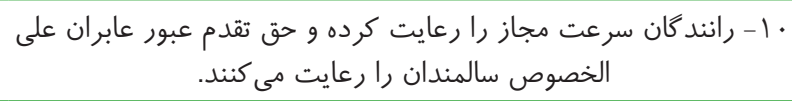 \\
\hline $\begin{array}{l}r / r V \\
(1 / 19)\end{array}$ & $\begin{array}{c}\mathcal{G} \\
(1 / \mathcal{F})\end{array}$ & $\begin{array}{l}9 \cdot \\
(Y / / 0)\end{array}$ & $\begin{array}{l}\Delta r \\
(I r / V)\end{array}$ & $\begin{array}{l}\operatorname{lrk} \\
(r r / 1)\end{array}$ & $\begin{array}{l}\ln (\mu / \mu) \\
(\mu r / \mu)\end{array}$ & 11 - به منظور سهولت تردد سالمندان، يِياده روهاى عريض در شهر \\
\hline $\begin{array}{l}r / r q \\
(1 / 1 \wedge)\end{array}$ & $\begin{array}{c}1 \mu \\
(\mu / 1)\end{array}$ & $\begin{array}{l}\Lambda r \\
(19 / 9)\end{array}$ & $\begin{array}{l}\Delta \cdot \\
(I r)\end{array}$ & $\begin{array}{l}\mid F r \\
(\mu F / r)\end{array}$ & $\begin{array}{l}1 \mu \cdot \\
(\mu / / 1)\end{array}$ & r ا - يِاده روها داراى سنگفرش هاى صاف و بدون مانع جهت سهولت \\
\hline $\begin{array}{l}r / F \varphi \\
(1 / r F)\end{array}$ & $\stackrel{1 \wedge}{(\boldsymbol{F} / \mu)}$ & $\begin{array}{l}91 \\
(r \mu / \mathcal{F})\end{array}$ & $\begin{array}{l}G r \\
(I F / \Lambda)\end{array}$ & $\begin{array}{l}|r| \\
(r N / 9)\end{array}$ & $\begin{array}{l}111 \\
(Y \wedge / r)\end{array}$ & سן - در مجاور پلهها مسير شيب دار مناسب جهت سهولت تردد \\
\hline $\begin{array}{l}r / 19 \\
(1 / 19)\end{array}$ & $\begin{array}{l}\mid r \\
(\Psi / \mu)\end{array}$ & $\begin{array}{l}V \cdot \\
(\mid s / V)\end{array}$ & $\begin{array}{l}\text { fr } \\
(1 \cdot / 0)\end{array}$ & $\begin{array}{l}(r / 1 / \Lambda) \\
(\mu r\end{array}$ & $\begin{array}{l}10 V \\
(r V / s)\end{array}$ & f ا - ايمنى در خيابان هاى محله به گونه اى است كه سالمندان مى توانند \\
\hline $\begin{array}{l}r / \Delta r \\
(1 / r \mu)\end{array}$ & $\begin{array}{l}\mid \mathcal{I f} \\
(\mu / \mu)\end{array}$ & $\begin{array}{l}V \cdot \\
(\mid \& / V)\end{array}$ & $\begin{array}{l}V D \\
(I V / 9)\end{array}$ & $\begin{array}{l}119 \\
(r \wedge / 0)\end{array}$ & $\begin{array}{l}1 \cdot V \\
(r \Delta / s)\end{array}$ & ه 10 - اطلاعات كافى براى نشان دادن مسير و همجنين علائم \\
\hline \multicolumn{7}{|c|}{$(q / \Lambda) \mu F / \Lambda$} \\
\hline
\end{tabular}

در شاخص خدمات سلامتى گو يه امكان دسترسى به خدمات متعارف يزشكى به طور رايكان براى سالمندان (كويه ه) با ميانكين

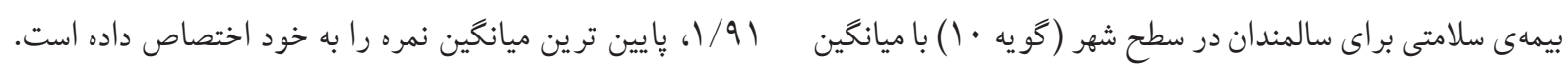

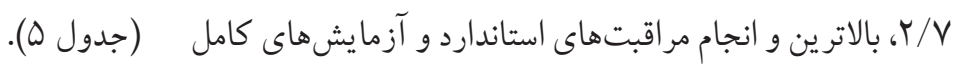

جدول ه. اطلاعات توصيفى شاخصخدمات سلامتى شهر تهران به تفكيك سوالات از ديدكاه سالمندان شركت كننده در يثوهش

\begin{tabular}{|c|c|c|c|c|c|c|}
\hline \multirow{2}{*}{ (انحراف معيار) } & \multicolumn{5}{|c|}{ تعداد (درصد ) } & \multirow{2}{*}{ 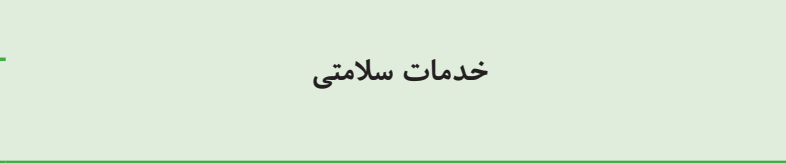 } \\
\hline & 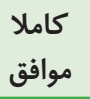 & موافق & 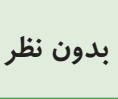 & مخالف & 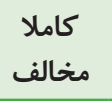 & \\
\hline $\begin{array}{l}r / \Delta F \\
(1 / \mu 1)\end{array}$ & $\begin{array}{l}1 \wedge \\
(\mathcal{F} / \mu)\end{array}$ & $\begin{array}{l}1 \mu \cdot \\
(\mu / / 1)\end{array}$ & $\begin{array}{l}\text { rs } \\
(\Lambda / \varphi)\end{array}$ & $\begin{array}{l}11 r \\
(r s / 1)\end{array}$ & $\begin{array}{l}1 r r \\
(r q / r)\end{array}$ & 1 - طراحى فيزيكى ساختمانهاى بزشكان، درمانغاهها، مطب استفادها و ... \\
\hline $\begin{array}{l}r / Y V \\
(1 / T r)\end{array}$ & $\begin{array}{c}19 \\
(1 / 0)\end{array}$ & $\begin{array}{l}\wedge \\
(19 / 1)\end{array}$ & $\begin{array}{l}r \Delta \\
(\Lambda / \mathcal{F})\end{array}$ & $\begin{array}{l}\mid F V \\
(Y \Delta / Y)\end{array}$ & $\begin{array}{l}(r r / N) \\
(r / N)\end{array}$ & r- نوبت دهى و خدمات رسانى ويز هاى به سالمندان در مراكز بهداشتى - \\
\hline $\begin{array}{l}r / r \Delta \\
(1 / r)\end{array}$ & $\begin{array}{l}11 \\
(\boldsymbol{F} / \mu)\end{array}$ & $\begin{array}{c}11 \\
(19 / 4)\end{array}$ & $\begin{array}{l}\Delta \mu \\
(I r / V)\end{array}$ & $\begin{array}{l}\mid F V \\
(r \Delta / r)\end{array}$ & $\begin{array}{l}119 \\
(r N / O)\end{array}$ & r- به خانوادهها در زمينه مراقبت از خود و مراقبت آماز ازم سالمندان خانواده \\
\hline $\begin{array}{l}(1 / 10) \\
(1 / 4\end{array}$ & $\begin{array}{l}19 \\
(1 / \Lambda)\end{array}$ & $\begin{array}{l}\text { is } \\
(11)\end{array}$ & $\begin{array}{l}V \Psi \\
(I V / 0)\end{array}$ & $\begin{array}{l}|r| \\
(r N / q)\end{array}$ & $\begin{array}{l}19 r \\
(r \wedge / \Lambda)\end{array}$ & 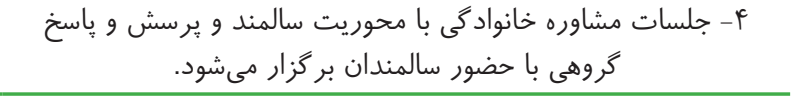 \\
\hline $\begin{array}{l}1 / 91 \\
(1 / \cdot \vee)\end{array}$ & $\begin{array}{c}V \\
(1 / V)\end{array}$ & $(1 \cdot / \mu)$ & $\begin{array}{l}\Delta 1 \\
(\mid r / r)\end{array}$ & $\begin{array}{l}(r q / r) \\
(r / 4\end{array}$ & $\begin{array}{l}190 \\
(f 4 / V)\end{array}$ & ه- مراقبت استاندارد و آزمايشهاى كامل متعارف ٍزشكى بطور رايگان \\
\hline $\begin{array}{l}r / 19 \\
(1 / 19)\end{array}$ & $\begin{array}{c}r \cdot \\
(r / \Lambda)\end{array}$ & $\begin{array}{l}\Delta F \\
(1 T / Q)\end{array}$ & $\begin{array}{l}90 \\
(10 / 9)\end{array}$ & $\begin{array}{l}\text { IrA } \\
(r \cdot / \mathrm{r})\end{array}$ & $\begin{array}{l}10 \cdot \\
(14)\end{array}$ & צ- خدمات بهداشتى و درمانى بطور مناسب بين سالمندان توزيع مىشود. \\
\hline
\end{tabular}




\begin{tabular}{|c|c|c|c|c|c|c|}
\hline $\begin{array}{l}r / 19 \\
(1 / 14)\end{array}$ & $\begin{array}{l}1 \\
(Y / \mathcal{F})\end{array}$ & $\begin{array}{l}s \mathcal{F} \\
(\mid \Delta / \mu)\end{array}$ & $\begin{array}{l}94 \\
(10 / \Lambda)\end{array}$ & $\begin{array}{l}(\mu r / \mu) \\
(r \mu \Delta)\end{array}$ & $\begin{array}{l}\mid F r \\
(\mu r / r)\end{array}$ & V- در مورد مراكز بهداشت و درمان به سالمندان اطلاعرسانى واضح و \\
\hline $\begin{array}{l}r / r \digamma \\
(1 / r \varphi)\end{array}$ & $\begin{array}{l}\text { r^ } \\
(\zeta / \mathrm{Y})\end{array}$ & $\begin{array}{l}\Delta \Lambda \\
(\mid r / q)\end{array}$ & $\begin{array}{l}\Delta S \\
(\mid r / \mathcal{F})\end{array}$ & $\begin{array}{l}\mid r F \\
(r q / V)\end{array}$ & $\begin{array}{l}10 \cdot \\
(1 \% / 9)\end{array}$ & ^- دسترسى به غذاى باكيفيت كه سالمند از عهدهى خريد آن بر آيد، \\
\hline $\begin{array}{l}r / r q \\
(1 / r \mu)\end{array}$ & $\begin{array}{c}1 \wedge \\
(\mathcal{F} / \mu)\end{array}$ & $\begin{array}{l}\vee q \\
(1 \wedge / 9)\end{array}$ & $\begin{array}{l}\Delta 1 \\
(\mid r / r)\end{array}$ & $\begin{array}{l}|\mu| \\
(\mu \mid / \mu)\end{array}$ & $\frac{1}{(r / \mu)}$ & 9 - امكان دسترسى به خدمات \\
\hline $\begin{array}{l}r / V \\
(1 / \mu 1)\end{array}$ & $\begin{array}{l}r \varphi \\
(\zeta / r)\end{array}$ & $\begin{array}{l}\mid r V \\
(r \cdot / \mathbb{F})\end{array}$ & $\begin{array}{l}\vee 1 \\
(I \vee)\end{array}$ & $\begin{array}{c}\wedge \Delta \\
(r \cdot / \mu)\end{array}$ & $\begin{array}{l}1 \cdot 9 \\
(r s / 1)\end{array}$ & • 1 - امكان دسترسى به خدمات بيمهى سلامتى در سطح شهر براى \\
\hline \multicolumn{7}{|r|}{ ميانگين (انحراف معيار)كل شاخص خدمات سلامتى شهر } \\
\hline
\end{tabular}

\section{بحث و نتيجه كيرى}

در مطالعهى انجام شده در تهران، از نظر متخصصان حوزهى سالمندى، مهمتر ين مشكلات موجود براى سالمندان در سطح شهر، وجود يستى و بلندى و اختلاف سطح زياد در ييادهروها؛ تجاوز

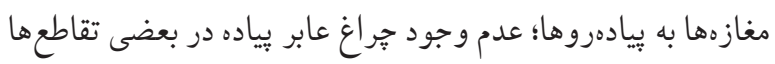

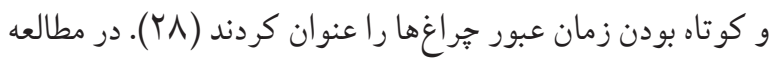

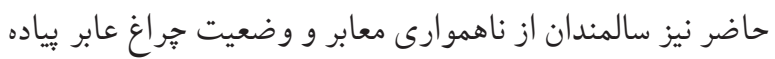

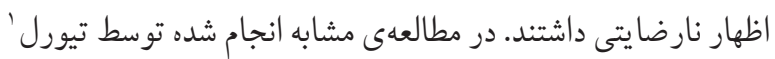
و همكاران در شهر ازمير تركيه آلودگى هوا، ترافيك، امنيت،

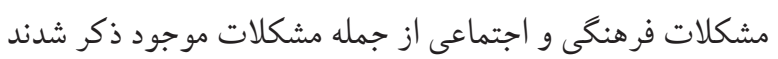

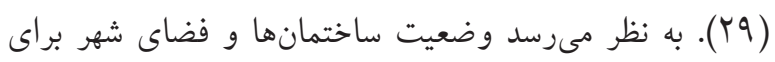

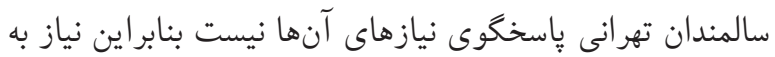
ايجاد ملاحظاتى در ساختمانها و فضاى شهرى توسط شهردارى و ساير مقامات مسئول وجود دارد. ميانخين كلى شاخص مسكن در مطالعه حاضر بالاتر از حد متوسط بود كه نشاند دهنده وضعيت مطلوب است. در اين شاخص، تناسب

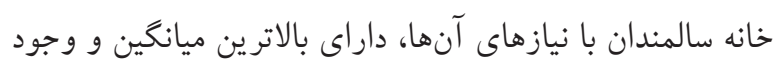

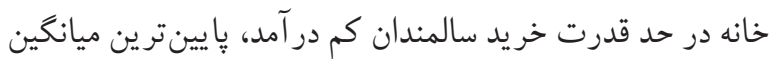

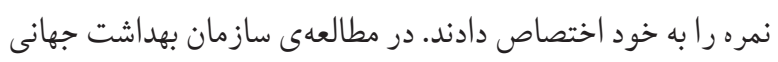

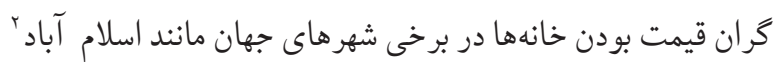

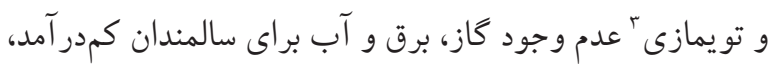

1. Turel

2. Islamabad

3. Tuymazy
مطالعه حاضر با هدف بررسى ديدكاههاى سالمندان در زمينه ميزان

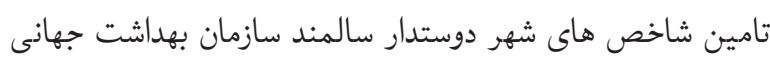
از نظر فضاهاى باز و ساختمان ها، مسكن، حمل و نقل و خدمات سلامتى در شهر تهران انجام شده است. بر اساس يافتهها، ميانگين كلى شاخص فضاهاى باز و ساختمانها، نزديك به حد متوسط بود. از

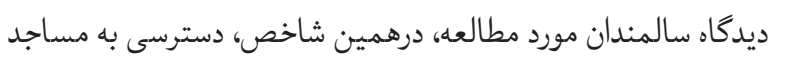

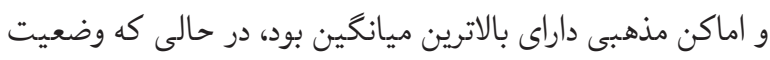

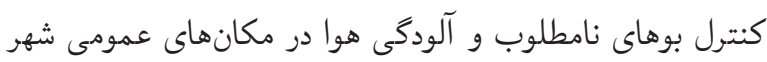

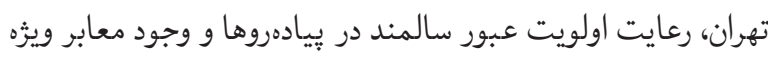
براى ويلجر و جرخ دستى در محل اتصال به خيابان اصلى داراى پايين ترين ميانخين بوده كه نامطلوب است. در مطالعهى سازمان

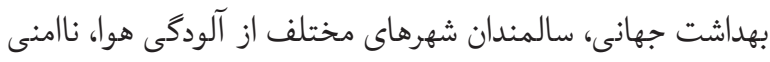
پاركها، كمبود صندلى براى نشستن، مناسب نبودن يِيادهروها،

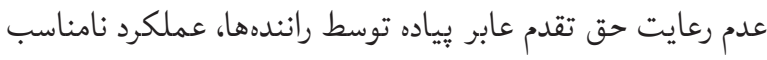

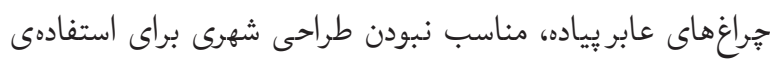

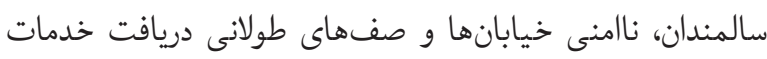
شكايت داشتند (Y)). در مطالعهى مشابه انجام شده درتهران (F) نيز سالمندان مورد مطالعه از عدم وجود صف يا ييشخوان مجزا در

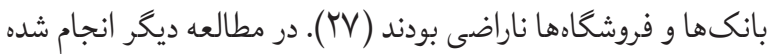
در شهر مشهد، سالمندان مشهدى از عدم دسترسى به سرويسهاى

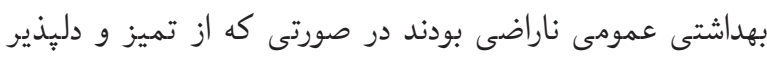
بودن شهر مشهد و وجود صندلى كافى در ايستخاههاى حمل و نقل عمومى اظهار رضايت داشتند (IT). 
سالمندان به اتومبيل شخصى و گو اهينامه، وسايل حملونقل عمومى

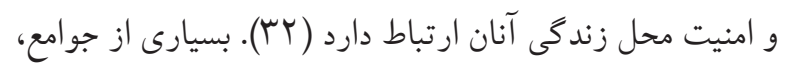

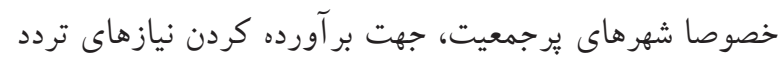

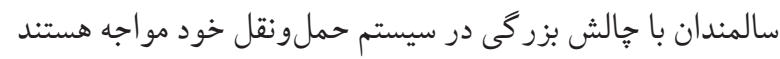
(ץT). در مطالعهى انجام شده در ايران، متخصصان سالمندى عنوان

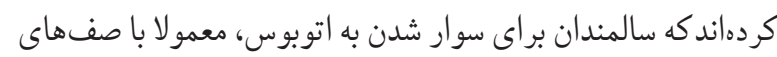

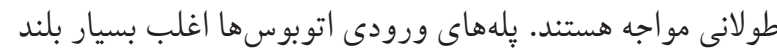

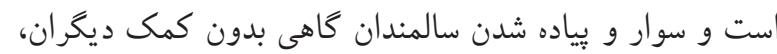
غير ممكن است، علاوه بر آن محل خاصى براى نشستن سالمندان

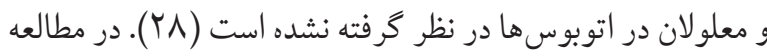

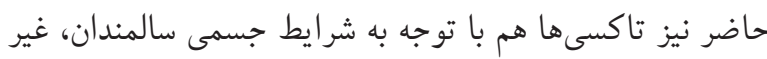

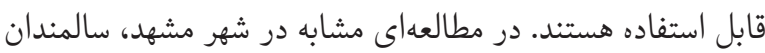
شركت كننده در مطالعه از وضعيت حملونقل براى سالمندان،

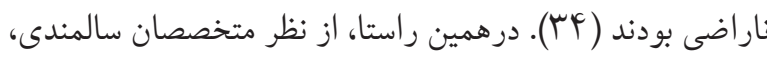
سيستم حمل و نقل شهر تهران وضعيت مطلوبى ندارد ( آس). اين در حالى است كه بهبود سيستم حمل و نقل مى تواند تاثير به سزايى

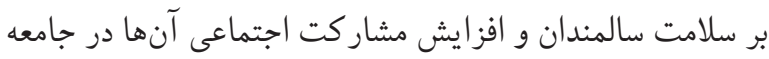

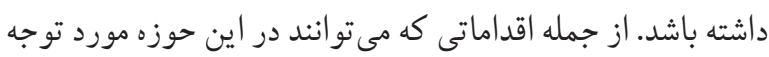
واقع شوند، در نظر كرفتن تخفيف ويزه براى سالمندان، در نظر

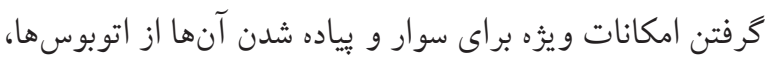
آموزش فرهنگ اولويت نشستن سالمندان به فرزندان، مطلع ساختن سالمندان دربارهى وسايل حمل ونقل موجود و برنامهها و ايستخاهها، بهبود وضعيت معابر از نظر تامين روشنايى در شب و عريض و و

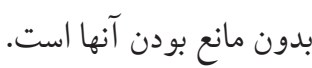

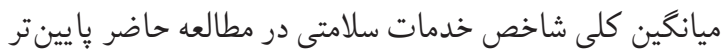
از حد متوسط بودكه بيانكر نامطلوب بودن وضعيت اسن شاخص

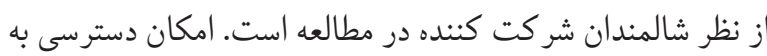
خدمات بيمهى سلامتى در سطح شهر براى سالمندان داراى بالاترين

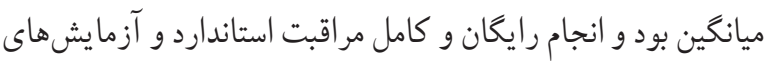
كامل متعارف بز شكى بطور رايگان براى سالمندان داراى پيايين ترين

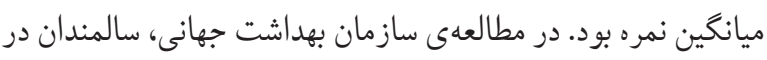

كران بودن كاز، برق و آب در مسكو'، عدم استفاده از مواد و

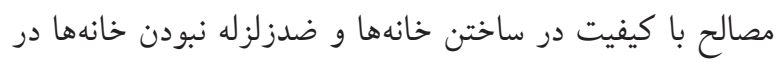
استانبول ' به عنوان قسمتى از مشكلات موجود در اين حيطه مطرح

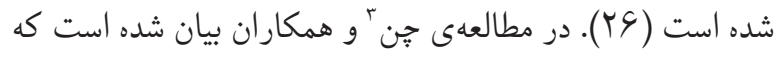

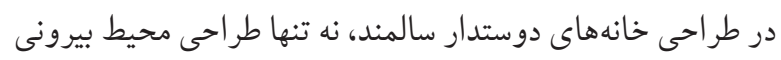

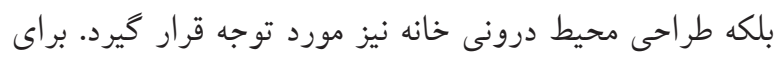
اين منظور بايد كمك هزينهاى براى سالمندانى كه نياز به تعديل

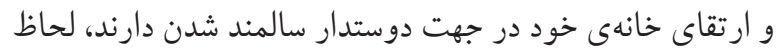

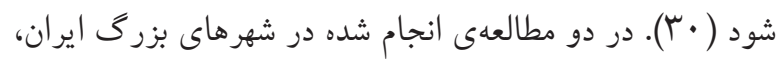

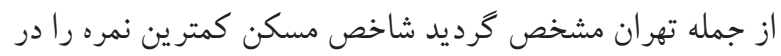

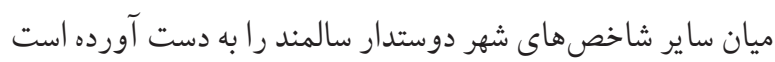

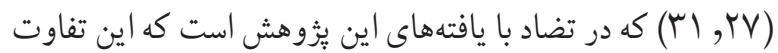

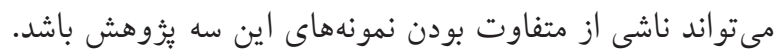

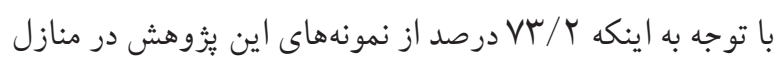
شخصى سكونت مى كردند و خانههاى خود را متناسب با نيازهاى خود تعديل كرده بودند، رضايت از اين شاخص در بين سالمندان اين بزوهش، قابل توجيه است.

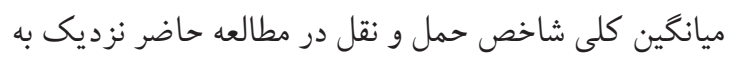
حد متوسط بود. در اين شاخص وجود مسير اتوبوس به مقصدهاى

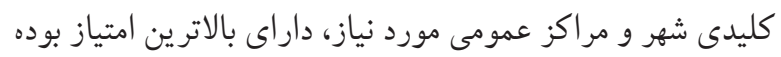

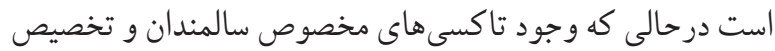
كارتهاى تخفيف ويزه به آنان داراى ڤي يين ترين ميانخين بود. در مطالعهى سازمان بهداشت جهانى فاكتورهايى مثل كرانى هز ينهى حمل ونقل، عدم وجود و سايل نقليهى عمومى به مقاصد كليدى شهر، دشوارى استفاده از وسايل حملونقل عمومى براى سالمندان، مناسب نبودن ايستخاههاى وسايل حملونقل، طراحى نامناسب تاكسى ها

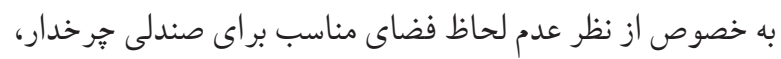

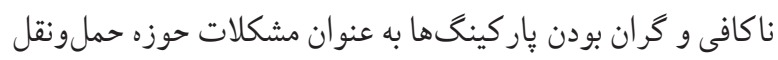

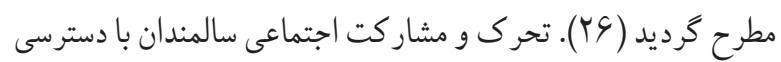


مراقبت از سالمندان، يِيشيرى و مديريت بيمارىهاى مزمن، نيازمند طراحى سياستهاى بايدار در مورد مراقبتهاى طولانى مدت در جهت

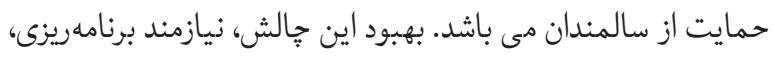
اجرا و ارزشيابى مداوم توسط شهردارى و ساير مقامهاى مسئول و

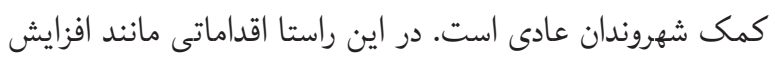

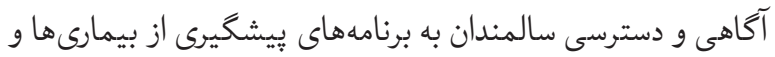
برنامههاى آموزشى، توزيع مناسب خدمات سلامتى، افزايش حمايت

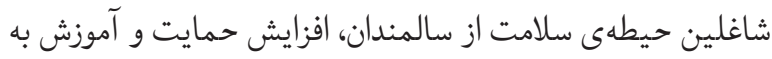
خانوادههاى سالمندان مى تواند مفيد واقع شود. لذا توصيه مى كردد كه اتخاذ سياستهايى براى ارتقا سطح كيفيت زندگى سالمندان، در اولويت برنامههاى مسئولين و مقامات قرار گيرد.

$$
\text { تقدل ير و تشكر أشوي }
$$

مقاله حاضر بركرفته از طرح مصوب دانشگاه علوم يزشكى شهيد

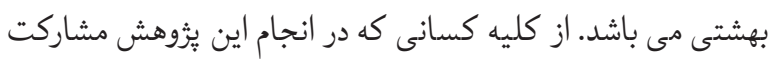

داشتند، بهخصوص سالمندان قدردانى مى گردد.

$$
\text { تضاد منافع }
$$

نويسندكان مقاله هيجگُونه تضاد منافعى ندارد.

\section{References}

1. Estebsari F, Dastoorpoor M, Mostafaei D, Khanjani $\mathrm{N}$, Khalifehkandi ZR, Foroushani AR, et al. Design and implementation of an empowerment model to prevent elder abuse: a randomized controlled trial. Clin Interv Aging. 2018;13:669-79. http s: / / doi org / 10.2147 / CIA.S 158097 PMid:29713151 PMCid:PMC5909776

2. Tehrani H. Mental health stigma related to novel coronavirus disease (COVID-19) in older adults. Geriatrics \& Gerontology International. 2020;20(8):796-7. h tt ps: / / d o i . org / 10.1111 /g gi . 13985 PMid:32639082 PMCid:PMC7361788

3. Rahaei Z, Mehrjoyan N, Barzegr F, Anbari-Nogyni Z. Is Higher Health Literacy Associated with Better Self-Care in the Elderly? Journal of Health Literacy. 2020;5(3):26-35.

4. Bastani F, Haghani H, Goodarzi P. Age-Friendly Cities Features From the Elderly's Perspectives Underscoring "Community Support and Health Services". Journal of Client-Centered Nursing Care. 2016;2(2):103-14.
بسيارى از نقاط جهان از گران قيمت بودن خدمات بزشكى شكايت

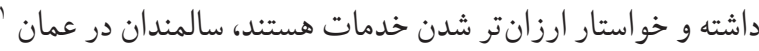

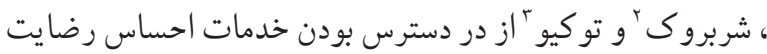

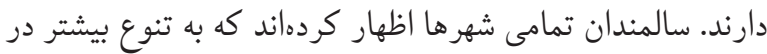

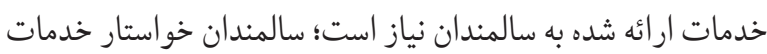

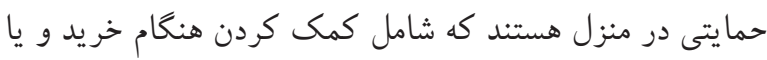

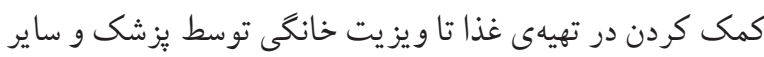

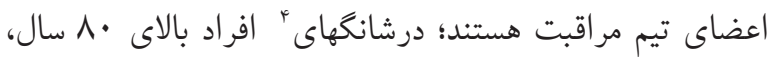

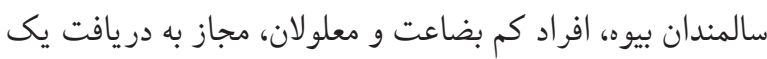

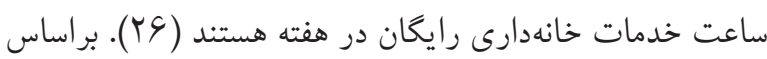
مطالعهى انجام شده در ايران مشخص كرديد كه با افزايش سن، به ويزه در دوران سالمندى، تقاضاى بخش بهداشت و درمان به

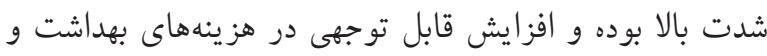

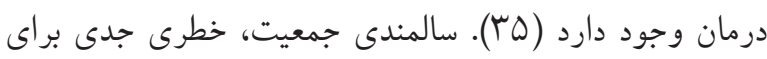
شروع جالش افزايش بيمارىهاى غيرمسرى و افزايش قابل توجه

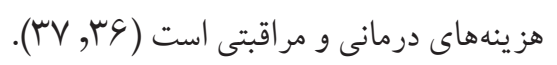

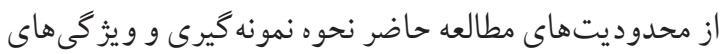

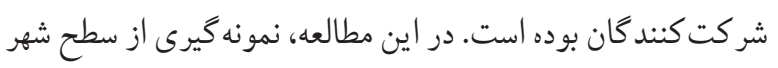

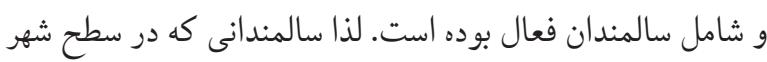
تردد داشتند، در اين يُزوهش شركت كردند و با توجه به ماهيت مطالعه امكان بررسى سالمندان منزوى در منازل و يا خانه سالمندان

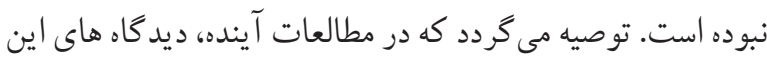
كروه سالمندان كه براى تردد درسطح شهر نياز به امكانات و شردايط خو اص هستند و يا ديد گاه خانو داها ى مراقبت كننده از سالمندان

$$
\text { نيز لحاظ كردد. }
$$

بر اساس يافتهاى يُزوهش حاضر، شاخص خدمات سلامتى كمترين

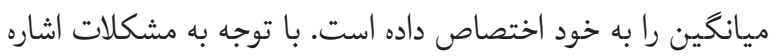

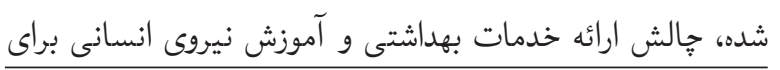

1. Oman

2. Sherbroook

3. Tokyo

4. Shanghay 
https://doi.org/10.32598/jccnc.2.2.103

5. Organization WH. The Global Network for Age-friendly Cities and Communities: Looking back over the last decade, looking forward to the next. World Health Organization, 2018.

6. Assawamaitree S, Hongsranagon P. The Association between the Perception of Age-Friendly City Features and the Mental Health Status of the Elderly in Photaram District, Ratchaburi Province, Thailand. Journal of Health Research. 2017;31(Suppl. 2):S137-42.

7. Lee KH, Kim S. Development of age-friendly city indicators in South Korea. Urban Design International. 2020;25(1):1-12. https://doi.org/10.1057/s41289-019-00078-6

8. Adib Roshan F, Talebpour M, Peymanizad H, Purazat AA. Identify the Characteristics of the Elderly-Friendly City in Iran 2050. Journal of vision Future Cities. 2020;1(2):51-61.

9. $\mathrm{Yu} R$, Wong $M$, Woo J. Perceptions of neighborhood environment, sense of community, and selfrated health: an age-friendly city project in Hong Kong. Journal of urban health. 2019;96(2):276-88. https://doi.org/10.1007/s11524-018-00331-3 PMid:30511137 PMCid:PMC6458199

10. Yousefi H, Sahzabi AY, Masih M, Ghaleh S, Mirzaaghabeik M. Urban parks prioritization concerning the age-friendly criteria in Sari, Northern Iran. International Journal of Occupational Hygiene. 2016;8(2):116-23.

11. Ahmadi A, Seyedin H, Fadaye-Vatan R. Towards agefriendly hospitals in developing countries: a case study in iran. Health Promot Perspect. 2015;5(1):42-51. https://doi.org/10.15171/hpp.2015.006 PMid:26000245 PMCid:PMC4430697

12. zarghani Dsh, kharazmi doa, johari I. Evaluating Spatial Physical indictors in Mashhad To become "Age-Friendly" City. Geography and Territorial Spatial Arrangement. 2015;5(15):177-96.

13. Taghdisi $\mathrm{MH}$, Estebsari $F$, Rahimi Foroushani A, Eftekhar Ardebili H, Shojaeizadeh D, Dastoorpoor M, et al. The educational programbasedonthesuccessfulagingapproach in elders health-promoting behaviors: A clinical trial study. Razi Journal of Medical Sciences. 2014;21(125):26-36. https://doi.org/10.5812/ircmj.16314

14. Taraghi Z, llali ES. A comparison of older adults' and managers' attitudes towards age-Friendly City indexes. Iranian Journal of Ageing. 2018;13(2):236-49. https://doi.org/10.32598/sija.13.2.236

15. World Health Organization. WHO global network of agefriendly cities. Switzerland: World Health Organizayion. 2009.
16. Warth L. The WHO global network of age-friendly cities and communities: Origins, developments and challenges. Age-friendly cities and communities in international comparison: Springer; 2016. p. 37-46. https://doi.org/10.1007/978-3-319-24031-2_3

17. Estebsari F, RahimiKhalifeh Kandi Z, Estebsari K, Mostafaei D. Elderly Friendly City Conceptsand Indicators. Iranian Journal of Health Education and Health Promotion. 2020;8(1):5-9. https://doi.org/10.29252/ijhehp.8.1.5

18. Alarcón A, Klicnik I, Dogra S. Perspectives on Active Transportation in a Mid-Sized Age-Friendly City: "You Stay Home". Int J Environ Res Public Health. 2019;16(24). https://doi.org/10.3390/ijerph16244916 PMid:31817340 PMCid:PMC6950044

19. Fitzgerald KG, Caro FG. An overview of agefriendly cities and communities around the world. Journal of Aging \& Social Policy. 2014;26(1-2):1-18. https://doi.org/10.1080/08959420.2014.860786 PMid:24224848

20. Organization WH. WHO Age-friendly cities project methodology: Vancouver protocol. Genebra; 2007.

21. Paiva NM, Daniel F. Age-friendly Coimbra city, Portugal, perception and quality of life in a sample of elderly persons. 2019;24(4):1473-82. https://doi.org/10.1590/1413-81232018244.08902017 PMid:31066849

22. Noordzij JM, Beenackers MA, Roux AVD, van Lenthe FJ. Age-friendly cities: challenges for future research. Bulletin of the World Health Organization. 2019;97(6):436. https: / / doi.org/10.2471/BLT.18.224865 PMid:31210682 PMCid:PMC6560366

23. Plouffe L, Kalache A. Towards global age-friendly cities: determining urban features that promote active aging. Journal of urban health. 2010;87(5):733-9. https://doi.org/10.1007/s11524-010-9466-0 PMid:20549569 PMCid:PMC2937125

24. center NR. Community Assessment Survey for Older Adults. Denver: 2015.

25. Jelokhani-Niaraki M, Hajiloo F, Samany NN. A web-based public participation GIS for assessing the age-friendliness of cities: A case study in Tehran, Iran. Cities. 2019;95:102471. https://doi.org/10.1016/j.cities.2019.102471

26. WorldHealthOrganization. Global age-friendly cities: A guide: Geneva; 2007.

27. Shariat F MF, Ghahramani R. Study of Social, Cultural, Economic, Well-Being, and Urbal Structure Needs of Tehran Seniors Association Members. Iranian Journal of Aging. 2015;10(3). 
28. Nemati D AH. Tehran as a Age Friendly City, Fist Step in Becoming Seniors Capital city. Social Research. 2014;6(18):15-44.

29. Turel HS, Yigit EM, Altug I. Evaluation of elderly people's requirements in public open spaces: A case study in Bornova District (Izmir, Turkey). Building and Environment. 2007;42(5):2035-45. https://doi.org/10.1016/j.buildenv.2006.03.004

30. Chan AW, Chan HY, Chan IK, Cheung BY, Lee DT. An AgeFriendly Living Environment as Seen by Chinese Older Adults: A "Photovoice" Study. International journal of environmental research and public health. 2016;13(9):913. https://doi.org/10.3390/ijerph13090913 PMid:27649217 PMCid:PMC5036746

31. Sharqi A, Zarghami E, Salehi Kousalari F, Olfat M. Evaluating status of global indices of age-friendly city in Tehran Metropolis (AFC). Journal of Urban - Regional Studies and Research. 2016:1-22. https://doi.org/10.21307/acee-2016-034

32. Levasseur M, Généreux M, Bruneau J-F, Vanasse A, Chabot $E$ É, Beaulac $C$, et al. Importance of proximity to resources, social support, transportation and neighborhood security for mobility and social participation in older adults: results from a scoping study. BMC public health. 2015;15(1):503. https://doi.org/10.1186/s12889-015-1824-0 PMid:26002342 PMCid:PMC4460861

33. Böcker L, van Amen P, Helbich M. Elderly travel frequencies and transport mode choices in Greater Rotterdam, the Netherlands. Transportation. 2017;44(4):831-52. https://doi.org/10.1007/s11116-016-9680-z

34. Zarghani H KO, Johari L. Evaluation of urban open spaces and inland urban transport in Mashhad based on the indicators of the Elderly Cities (collaborative approach). Urban Management and Planning. 2014;5(15):177-96.

35. MirzaieM,DarabiS. PopulationAgingin Iranand Rising Health Care Costs. Iranian Journal of Ageing. 2017;12(2):156-69. https://doi.org/10.21859/sija-1202156

36. Foroushani AR, Estebsari F, Mostafaei D, Ardebili HE, Shojaeizadeh D, Dastoorpour $M$, et al. The effect of health promoting intervention on healthy lifestyle and social support in elders: a clinical trial study. Iranian Red Crescent Medical Journal. 2014;16(8). https://doi.org/10.5812/ircmj.18399

37. Estebsari F, RahimiKhalifeh KandiZ, Estebsari K, Mostafaei D. ElderlyFriendly City Conceptsand Indicators. Iranian Journal of Health Education and Health Promotion. 2020;8(1):5-9. https://doi.org/10.29252/ijhehp.8.1.5 